\title{
La garantía de prioridad de permanencia de los representantes de los trabajadores en el despido colectivo
}

\section{The guarantee of permanence priority of workers' representatives in collective dismissals}

\author{
Juan Alberto Tormos Pérez* \\ Profesor Ayudante Doctor \\ Universitat de València \\ ORCID ID: 0000-0001-8829-192X
}

Recibido: 08/06/2020

Aceptado: $15 / 07 / 2020$

doi: https://doi.org/10.20318/labos.2020.5777

\begin{abstract}
Resumen: $\quad$ En la presente contribución se analiza la prioridad de permanencia de los representantes de los trabajadores como límite a la facultad del empresario de seleccionar a los trabajadores afectados por el despido colectivo. Se estudia su conexión con las funciones representativas así como con la libertad sindical, y se detalla su operatividad aplicando la lógica de la sustitución. Si bien la garantía no es esgrimible con carácter absoluto, la inclusión entre los afectados de un titular de la misma requiere que el empresario aporte una justificación expresa. Finalmente, se enumeran los sujetos beneficiarios de la garantía, así como la necesidad de que los representantes tengan el mandato vigente en el momento de aplicarla.

Palabras clave: representantes de los trabajadores, garantías, prioridad de permanencia, despidos colectivos.

Abstract: This contribution analyses the guarantee of permanence priority of workers' representatives as a limit to the employer's power to select the workers affected by collective dismissals. It studies the connection with representative functions as well as with freedom of business, and it details its functioning applying the logic of substitution. Although the guarantee is not absolute, the inclusion of a guarantee holder among affected workers requires the employer to provide an express justification. Finally, the beneficiaries of the guarantee are listed, as well as the need for the representatives to have the mandate in force at the time of applying it.

Keywords: $\quad$ workers representatives, guarantees, permanence priority, collective dismissals.
\end{abstract}

\section{Introducción y caracterización general}

A fin de situar el objeto de estudio del presente trabajo, hay que señalar que la selección de los trabajadores afectados por el despido colectivo debe respetar las conocidas como reglas de prioridad de permanencia. Las reglas de prioridad de permanencia implican, como su nombre indica, que

\footnotetext{
*juan.tormos@uv.es
} 
determinados colectivos tienen preferencia o prioridad para permanecer en la empresa y, por tanto, no verse afectados por el despido colectivo proyectado por el empresario. De hecho, dichas reglas de prioridad de permanencia operan como el principal límite a la facultad empresarial de seleccionar a los trabajadores afectados en los despidos colectivos, de modo que el empresario, a la hora de designar a los trabajadores afectados por la medida extintiva, deberá respetar dichas reglas.

Además de las reglas de prioridad de permanencia que para determinados colectivos puedan establecerse vía convencional -es decir, bien en convenio colectivo o bien mediante acuerdo alcanzado en el período de consultas-, el empresario viene obligado a respetar la regla de prioridad de permanencia establecida legalmente para los representantes legales de los trabajadores, que es la segunda garantía que el art. 68 ET les reconoce. ${ }^{1}$ De hecho, el art. 68 apartado b) de la Ley del Estatuto de los Trabajadores (ET) seńala: "Los miembros del comité de empresa y los delegados de personal, como representantes legales de los trabajadores, tendrán, a salvo de lo que se disponga en los convenios colectivos, las siguientes garantías: [...] b) Prioridad de permanencia en la empresa o centro de trabajo respecto de los demás trabajadores, en los supuestos de suspensión o extinción por causas tecnológicas o económicas." ${ }^{2}$ Dicha referencia que señala "a salvo de lo que se disponga en los convenios colectivos" se refiere precisamente al hecho de que los convenios colectivos podrán establecer otras garantías para los representantes que vayan más allá de las establecidas legalmente, pero no podrán en ningún caso restringirlas.

Por su parte, la prioridad se aplica con independencia de que en el período de consultas se haya alcanzado acuerdo o no, ya que la norma no distingue al respecto. ${ }^{3}$ Por tanto, el acuerdo alcanzado en período de consultas no puede soslayar la garantía de prioridad de permanencia reconocida legalmente.

La garantía de prioridad de permanencia viene también expresamente contemplada para los despidos colectivos en el art. 51.5 ET, cuyo primer inciso señala que "los representantes legales de los trabajadores tendrán prioridad de permanencia en la empresa en los supuestos a que se refiere este artículo". El mismo apartado recoge expresamente la posibilidad de que "mediante convenio colectivo o acuerdo alcanzado durante el periodo de consultas se podrán establecer prioridades de permanencia a favor de otros colectivos", y alude en concreto a colectivos como los trabajadores con cargas familiares, los mayores de determinada edad o las personas con discapacidad. Esta mención, si bien no era necesaria, tiene un claro objetivo promocional de esta garantía para colectivos que pueden tener dificultad para encontrar un nuevo empleo.

No obstante, el presente estudio se centra en la garantía tal y como se reconoce en el Estatuto de los Trabajadores para los representantes legales de los trabajadores. Dicha garantía tiene, además, proyección expresa sobre otros colectivos con funciones representativas. Así, en el plano normativo, debe añadirse también la previsión del art. 10.3 de la Ley Orgánica 11/1985, de 2 de agosto, de Libertad Sindical (LOLS), que amplía la garantía para los delegados sindicales en los casos en que no formen parte del comité de empresa; así como la Ley 31/1995, de Prevención de Riesgos

${ }^{1}$ Sobre las garantías de los representantes en detalle, véase TUDELA CAMBRONERO, Gregorio, Las garantías de los representantes de los trabajadores en la empresa. Madrid, Tecnos, 1988; GARCÍA MURCIA, Joaquín, Las garantías de los representantes de los trabajadores frente al despido: el tránsito hacia la unificación de doctrina, En: AA.VV., El Estatuto de los Trabajadores en la jurisprudencia del Tribunal Supremo. Estudios dedicados al Catedrático y Magistrado Don Antonio Martín Valverde, Madrid, Tecnos, 2015; SEMPERE NAVARRO, Antonio Vicente, Las garantías de los miembros del comité de empresa. Civitas: Revista Española de Derecho del Trabajo. España, Civitas, núm. 100, 2, 2000, p. 1317-1340; y SEMPERE NAVARRO, Antonio Vicente, PÉREZ CAMPOS, Ana Isabel, Las garantías de los representantes de los trabajadores (Estudio del Artículo 68 ET). Navarra, Aranzadi, 2004.

${ }^{2}$ La referencia a causas "tecnológicas y económicas" ha quedado obsoleta, pues se refiere a redacciones actualmente no vigentes de otros artículos del Estatuto de los Trabajadores. Por ello, hay que entender que se refiere a las actuales causas económicas, técnicas, organizativas o de producción, es decir, causas empresariales. Así lo ha señalado expresamente la STSJ de Galicia, de 15 de marzo de 2013 (Ro. 6268/2012), y también CID BABARRO, Carlos, La representación sindical de la empresa. Valladolid, Lex Nova, 2014, p. 227.

${ }^{3}$ Así lo señala la STS de 23 de septiembre de 2008 (Ro. 7678/2005, Sala de lo Contencioso-Administrativo). 
Laborales (LPRL), que extiende la prioridad de permanencia a los delegados de prevención (art. 37.1 LPRL), y también a los "trabajadores designados por el empresario para ocuparse de tareas de prevención" y miembros del servicio de prevención (art. 30 LPRL). Por motivos metodológicos, el ámbito subjetivo de la garantía se comenta en el epígrafe 5 del presente estudio, una vez analizada la garantía como tal.

Si bien no constituye el objeto de este trabajo, cabe señalar que la prioridad de permanencia de los representantes de los trabajadores también se aplica en otros supuestos distintos del despido colectivo. Así, el art. 52 c) ET la contempla expresamente para los despidos objetivos por causas empresariales que no tengan carácter colectivo, es decir, individuales o plurales. En aquellos despidos objetivos en los que el empresario disponga de varias alternativas de selección, la garantía de prioridad de permanencia debe entenderse con el mismo alcance que la garantía contenida en el art. 51.5 ET para los despidos colectivos, tanto en lo relativo a las condiciones para beneficiarse de la misma, su ámbito de aplicación o alcance, así como en lo relativo a los titulares de la misma.

La prioridad de permanencia también es aplicable en los supuestos de suspensión del contrato de trabajo por causas empresariales ex art. 47.1 ET, ya que el art. 68 b) ET se refiere también a los supuestos de "suspensión" del contrato. Del mismo modo, el art. 40.7 ET reconoce a los representantes legales de los trabajadores prioridad de permanencia en su puesto de trabajo en los supuestos de movilidad geográfica, y como no especifica otra cosa, cabe entender que se refiere tanto a los traslados definitivos como a los desplazamientos temporales.

En otras figuras jurídico-laborales, en cambio, no se reconoce ningún derecho a la prioridad de permanencia para los representantes de los trabajadores. Tal es el caso de la sucesión o transmisión de empresa del art. 44 ET. Así lo ha recordado la SAN de 9 de octubre de 2017 (Procedimiento núm. 195/2017), al señalar que "la primera cuestión que hemos de descartar al respecto es que las garantías de permanencia que el art. 68 ET establece para los representantes unitarios de los trabajadores [...] puedan aplicarse a los supuestos de sucesión de empresas por transmisión de unidad productiva autónoma, donde la afectación a la sucesión viene determinada por la adscripción a la unidad que se trasmite, resultando irrelevante sobre este punto que el mandato representativo del trabajador en cuestión se extienda a toda la empresa o a un concreto centro de trabajo." ${ }^{4}$

No obstante, el presente estudio se centra en la prioridad de permanencia de los representantes de los trabajadores en los supuestos de despido colectivo del art. 51 ET. En este sentido, cabe señalar que la prioridad de permanencia de los representantes de los trabajadores, y en particular de los representantes legales, es una cuestión extensamente tratada por la doctrina. ${ }^{5}$ La prioridad de permanencia que contempla la ley para los representantes de los trabajadores supone una de las pocas limitaciones expresas a la facultad del empresario para seleccionar a los trabajadores afectados en el despido colectivo, hecho que ha determinado que dicha figura reciba un tratamiento expreso por la doctrina.

En la doctrina clásica, ALBIOL MONTESINOS aborda expresamente la cuestión de la garantía de prioridad de permanencia de los representantes de los trabajadores. ${ }^{6}$ Así, señala que esta garantía, además de en los procedimientos de despido colectivo, se aplica también en los supuestos de extinción o suspensión del contrato de trabajo por fuerza mayor, ya que el art. 51.5 ET señala que la

${ }^{4}$ Además, la citada sentencia señala como argumento que el propio art. 44.5 ET regula la situación de los representantes tras la transmisión, señalando que la misma "no extinguirá por sí mismo el mandato" de los representantes.

${ }^{5}$ En este sentido, destacan ALBIOL MONTESINOS, Ignacio, Extinción del contrato de trabajo por causas económicas o tecnológicas, En: BORRAJO DACRUZ, Efrén (dir.), Comentarios a las leyes laborales. El Estatuto de los Trabajadores, Tomo IX, Vol. 2, Artículos 49.5 a 9 y 51, Madrid, Edersa, 1989, p. 329-332; TUDELA CAMBRONERO, Las garantías de los representantes de los trabajadores en la empresa, ob. cit.; y RODRÍGUEZ RAMOS, María José, Despido colectivo: procedimiento, En: GORELLI HERNÁNDEZ, Juan (coord.), El despido: análisis y aplicación práctica, Madrid, Tecnos, 2004, p. 531-533.

${ }^{6}$ ALBIOL MONTESINOS, Ignacio, El sindicato en la empresa. Madrid, Editorial Deusto, 1990, p. 165-166. 
garantía se aplica "en los supuestos a que se refiere este artículo". Por otro lado, también indica que la preferencia no es absoluta, como se abordará en el epígrafe 3, ya que no opera respecto de cualesquiera trabajadores en la empresa, sino que opera respecto de los trabajadores que resulten afectados por el despido, y dentro de los grupos profesionales a los que pertenezcan los representantes de los trabajadores. De hecho, así lo señaló desde un primer momento el Tribunal Supremo, pronunciándose en este sentido la STS de 19 de mayo de 1980 (RJ 1859, Sala de lo Contencioso-Administrativo), en un supuesto de cierre total de la empresa en el que no era posible que operase la garantía. ${ }^{7}$

El presupuesto, por tanto, que permite operar a la garantía de prioridad de permanencia es la existencia de varios puestos de trabajo sobre los que se proyecta la causa extintiva alegada, de modo que el empresario deba realizar una selección o expresar una preferencia por un trabajador u otro, encontrándose estos en una situación profesional equivalente. En ese supuesto, hay un trabajador que tiene prioridad para permanecer en la empresa: el representante de los trabajadores. De este modo, la prioridad de permanencia excluye de la selección al trabajador que goza de la garantía, determinando que la elección se haga con respecto a otro trabajador que no goza de dicha garantía. La prioridad de permanencia se traduce, pues, en un "sacrificio potencial" para los otros trabajadores incluidos en el ámbito de afectación de la garantía pero que no son titulares de la misma. ${ }^{8}$ Dicha garantía, en tanto que limita la posibilidad de elegir a unos trabajadores u otros, constituye, como se ha señalado, un límite a la facultad de selección de que dispone el empresario, el cual, aun dentro de su ámbito discrecional, deberá respetar las reglas relativas a la prioridad de permanencia.

La jurisprudencia del Tribunal Supremo ha ido delimitando desde los primeros ańos tras la aprobación del Estatuto de los Trabajadores de 1980 cuáles son los parámetros de operatividad de dicha garantía. Así, la STS de 27 de julio de 1989 (RJ 5926, Sala de lo Social) señala que el "presupuesto implícito" para que opere la garantía de prioridad de permanencia es que haya dos o más trabajadores respecto de los cuales pueda establecerse algún tipo de prioridad o preferencia, pues de lo contrario no hay prioridad alguna. En dicha sentencia se establece que la prioridad de permanencia lo es en el "puesto de trabajo", por lo que hay que atender al hecho de si la actividad realizada por el titular de la garantía es individualizada, o en cambio su actividad es indiferenciada o polivalente. Sólo en el caso de que su actividad sea indiferenciada con respecto a las funciones desempeñadas por los trabajadores que ocupan otros puestos, podrá operar la garantía de prioridad de permanencia de los representantes de los trabajadores a la hora de amortizar un puesto. En cambio, si la actividad desempeñada es individualizada o no susceptible de intercambiarse con otros puestos, la aplicación de la garantía no sería posible.

Por su parte, a diferencia de la regulación normativa existente antes de la aprobación del Estatuto de los Trabajadores de 1980, que preveía en múltiples disposiciones reglamentarias una exhaustiva lista de prioridades, ${ }^{9}$ llamadas "preferencias", para permanecer en la empresa y aplicadas a diversos colectivos, la actual regulación de las prioridades de permanencia de origen legal se ciñe, con carácter principal, a la mencionada de los representantes legales de los trabajadores. En este sentido, ya el Estatuto de los Trabajadores de 1980 dejó virtualmente sin aplicación el antiguo y complejo sistema de "preferencias", al contemplar la prioridad de permanencia de los representantes legales de los trabajadores. En la actualidad, el art. 51.5 ET, en conexión con el art. 68 b) ET, viene

\footnotetext{
${ }^{7}$ La citada sentencia señala: “[la garantía] otorga un derecho que lógicamente habrá de estar condicionado a aquellos supuestos [...] que hagan posible la preferencia dentro de una relación que subsiste.”

${ }^{8}$ En la doctrina, así lo señalan BLASCO PELLICER, Ángel Antonio, Los expedientes de regulación de empleo. València, Tirant lo Blanch, 2009, p. 114; y SAMPER JUAN, Joaquín, Los sistemas tradicionales y el régimen español de participación de los trabajadores, En: AA.VV., Gobierno de la empresa y participación de los trabajadores: viejas y nuevas formas institucionales, Salamanca, AEDTSS-Universidad de Salamanca, 2006, p. 248.

${ }_{9}^{9}$ Así, por ejemplo, cabe citar el Decreto 3090/1972, de 2 de noviembre, sobre política de empleo (BOE 15/11/1972), que en el art. 15 señalaba que las extinciones se llevarían a cabo, como norma general, según el orden inverso al de antigüedad en la empresa.
} 
desarrollado reglamentariamente por el art. 13.1 del Reglamento de los procedimientos de despido colectivo (RPDC) de 2012, ${ }^{10}$ que básicamente reitera las previsiones legales al respecto.

\section{Justificación de la existencia de la prioridad de permanencia para los representantes de los trabajadores y su relevancia constitucional}

Que la regulación legal contemple, como principal limitación expresa a la facultad empresarial de seleccionar a los trabajadores afectados por el despido colectivo, una regla de prioridad de permanencia, y que dicha regla beneficie expresamente -y sin perjuicio de otros colectivos- a los representantes legales de los trabajadores, significa que el legislador ha querido proporcionar una especial protección a dicho colectivo y proteger su función representativa.

Precisamente, la razón de dicha protección radica en la "protección a las funciones" que desempeñan dichos representantes de los trabajadores, de modo que en caso de despido colectivo puedan permanecer en la empresa y continuar ejerciendo las mismas sin que se vean mermadas o afectadas por una reestructuración empresarial. Con ello, el legislador pretende evitar que los trabajadores queden sin representantes tras una reestructuración.

Pero, además, dicha prioridad pretende también evitar con carácter preventivo las posibles discriminaciones en las que el empresario puede estar tentado de incurrir en caso de seleccionar para su afectación por el despido colectivo a trabajadores en función de su cargo representativo o tareas sindicales. ${ }^{11}$ En definitiva, se trata de evitar abusos por parte del poder empresarial, que podría tener un interés en penalizar a los trabajadores que ejercen funciones representativas.

La existencia de la garantía de prioridad de permanencia pone de manifiesto la existencia de distintos intereses en juego en el despido colectivo, y a los que el legislador pretende otorgar un equilibrio. Por un lado, si bien el instituto del despido colectivo presupone un marco discrecional de decisión del empresario en el marco del principio constitucional de libertad de empresa (art. $38 \mathrm{CE}$ ), no puede olvidarse, por otro lado, que las relaciones laborales están condicionadas por el reconocimiento del principio de Estado social. En consecuencia, la libertad del empresario debe ponderarse con otros intereses legítimos de carácter social, como son el derecho al trabajo (art. 35 CE) y a no ser despedido sin justa causa, y también los derechos de índole representativa y el derecho fundamental a la libertad sindical (art. 28.1 CE).

La garantía de prioridad de permanencia protege, de este modo, a los representantes de los trabajadores frente al despido. El razonamiento radica en la idea según la cual protegiendo las funciones representativas de los representantes legales de los trabajadores se están protegiendo también los intereses de los trabajadores representados, aunque la existencia de la prioridad de los representantes supone un mayor riesgo de afectación potencial para los trabajadores que no lo son. En este sentido, si bien cabría plantear cierto debate en torno a la conceptualización de la garantía de prioridad de permanencia como una prerrogativa o como un privilegio, lo cierto es que la mayoría de la doctrina la entiende como una prorrogativa, con la misma naturaleza que el resto de garantías que prevé el art. $68 \mathrm{ET}$, y que pretenden garantizar que las funciones representativas puedan ejercerse de manera efectiva.

En el mismo sentido se ha pronunciado el Tribunal Constitucional, que en la STC 191/1996 de 26 de noviembre (Ro. 1804/1994 y 483/1995) señala que "al conceder la garantía de la prioridad

\footnotetext{
${ }^{10}$ Real Decreto 1483/2012, de 29 de octubre, por el que se aprueba el Reglamento de los procedimientos de despido colectivo y de suspensión de contratos y reducción de jornada (BOE 30/10/2012).

${ }^{11}$ Así lo expresa CERVERA SOTO, Teresa, CID BABARRO, Carlos, El despido colectivo: claves prácticas y análisis jurisprudencial. Valladolid, Lex Nova, 2016, p. 188.
} 
de permanencia la ley no concede un privilegio, sino que se tutela con esa garantía la representación de los trabajadores". ${ }^{12}$

También en la misma línea se ha pronunciado el Tribunal Supremo en jurisprudencia posterior. Así, la STS de 6 de mayo de 2003 (Ro. 7034/1998, Sala de lo Contencioso-Administrativo); STS de 4 de mayo de 2004 (Ro. 3687/2001, Sala de lo Contencioso-Administrativo); STS de 3 de febrero de 2009 (Ro. 101/2006, Sala de lo Social); STS de 18 de marzo de 2009 (Ro. 879/2007, Sala de lo Contencioso-Administrativo); y la STS de 27 de noviembre de 2018 (Ro. 1157/2016, Sala de lo Contencioso-Administrativo), lo expresan señalando que la garantía de prioridad de permanencia en la empresa de los representantes de los trabajadores tiene un "carácter instrumental de garantía del desempeño de sus funciones representativas".

Ahora bien, además de la protección de la representación en sí misma, dichas funciones representativas y su garantía suponen, en determinados casos, una manifestación del derecho fundamental a la libertad sindical reconocido en el art. 28.1 CE, que protege a su vez la composición de los órganos de representación cuando sus integrantes están sindicalizados. Por ello, la garantía supone también un "medio de protección" del representante de los trabajadores frente a decisiones discriminatorias del empresario que pudieran afectar al derecho fundamental de libertad sindical, cuando el representante está afiliado a alguna organización sindical. Se trata de una protección que actúa con carácter previo, excluyendo al representante de la posibilidad de selección, y por tanto de sufrir discriminación. ${ }^{13}$

Por lo tanto, la garantía de prioridad de permanencia tiene un carácter instrumental con respecto al desempeño de las funciones representativas, las cuales pretende garantizar en sí mismas; y además pretende proteger a los representantes sindicalizados frente a decisiones discriminatorias, en tanto que entra en juego el derecho fundamental a la libertad sindical reconocido en el art. 28.1 CE. ${ }^{14}$

En definitiva, se trata de una manera de proteger con carácter previo a los representantes de los trabajadores frente a decisiones empresariales de carácter discriminatorio, en supuestos de representantes sindicalizados, y a su vez proteger a los órganos de representación de alteraciones en su composición.

Por todo ello, la garantía de prioridad de permanencia de los representantes de los trabajadores tiene una clara relevancia constitucional. Así, la prioridad de permanencia de los representantes de los trabajadores está conectada con el derecho fundamental a la libertad sindical del art. 28.1 CE, cuando los órganos de representación están sindicalizados. La citada STC 191/1996 de 26 de noviembre, ya tuvo ocasión de pronunciarse al respecto, reconociendo expresamente que la prioridad de permanencia de los representantes de los trabajadores se integra en el derecho fundamental de libertad sindical.

${ }^{12}$ La STS de 11 de junio de 1984 (RJ 3190, Sala de lo Contencioso-Administrativo), en cambio, se expresó en unos términos que podían conducir a confusión, ya que consideró la prioridad de permanencia como un "beneficio" y hablaba de una "privilegiada continuidad" en la empresa que no podía aplicarse cuando la extinción atendía a motivos ajenos a la actividad representativa.

${ }^{13}$ La STSJ de País Vasco, de 17 de junio de 2014 (Ro. 21/2014) señala, con cita a la STC 191/1996, de 26 de noviembre, que la garantía de prioridad de permanencia "provoca que en la selección de los trabajadores afectados por la medida extintiva, los representantes de los trabajadores sigan teniendo una posición diferenciada y preferente respecto del resto de trabajadores en plantilla, que aun cuando no es un privilegio, sino que tiene un carácter instrumental de protección reforzando garantías de independencia y desempeño de funciones representativas, pretende evitar restricciones, máxime cuando se integra en el derecho de libertad sindical completo."

${ }^{14}$ En tanto que derecho fundamental, la libertad sindical se ejerce principalmente a través de los órganos de representación en la empresa, y ello es así, especialmente, como señala la citada STC 191/1996, de 26 de noviembre, en el F.J. 50, cuando la empresa cuenta con un comité "sindicalizado", es decir, cuando sus miembros están mayoritariamente afiliados a un sindicato y han accedido al comité de empresa a través de la candidatura presentada al efecto por dicho sindicato. La SAN de 12 de junio de 2013 (Procedimiento núm. 143/2013), y la STS de 14 de octubre de 2014 (Ro. 3054/2013, Sala de lo Social), señalan que "la prioridad de permanencia en la empresa a favor de los representantes de los trabajadores [...] tiene, por otra parte, [...] un carácter instrumental de garantía del desempeño de sus funciones representativas, como manifestación del derecho fundamental de libertad sindical que reconoce el artículo 28 de la Constitución.” 
El supuesto que se abordaba en dicho caso era el relativo a la inclusión de los representantes de los trabajadores en el listado de afectados que se presentaba en aquel momento a la autoridad laboral para solicitar la autorización para efectuar las extinciones. ${ }^{15}$ En aquel contexto, la inclusión de los representantes de los trabajadores se efectuaba con constancia de su condición de tal, y además, en el anexo de la solicitud se señalaba expresamente que la inclusión de los mismos era "a reserva del ejercicio por cada uno de ellos de la garantía de prioridad de permanencia que establece el art. 68 b) ET", de suerte que si ejercitaban dicha garantía, los representantes serían sustituidos por otros trabajadores no incluidos entre los afectados y que no disfrutan de la garantía.

Cuando posteriormente la empresa fue autorizada a efectuar las extinciones, los afectados recibieron una carta de despido que señalaba: "en el supuesto de que Vd. ostente la condición de representante de los trabajadores y siempre que decida hacer uso de la garantía otorgada por el art. 68 b) del Estatuto de los Trabajadores, deberá ponerlo en conocimiento de la Dirección de la Empresa por escrito, en el plazo máximo de cinco días, contados a partir de la recepción de la presente notificación. De no producirse su comunicación en el plazo indicado, se entenderá que no desea hacer uso de aquel derecho. Si, por el contrario hiciese uso de la garantía citada, será sustituido por otro trabajador de la plantilla de la empresa."

Tras la impugnación por parte de los representantes afectados, el Juzgado de lo Social núm. 1 de Oviedo, consideró, en Sentencia de 23 de noviembre de 1993, que la garantía de prioridad de permanencia no era absoluta, y por tanto era renunciable, por lo que no apreció que se vulnerase la libertad sindical de los representantes, destacando que se les dio opción a ejercitar la garantía de la que eran titulares. Consideraciones similares efectuó la STSJ de Asturias, de 29 de abril de 1994 (AS 1552), señalando que los representantes no alegaron la vulneración de sus derechos sindicales en su momento, haciendo una nítida "dejación voluntaria" de sus derechos.

Interpuesto recurso de amparo, los recurrentes alegaban el hecho de que "la actividad sindical también se ejerce en las empresas mediante la participación en los órganos de representación de los trabajadores", doctrina establecida en la STC 9/1988 de 25 de enero (Ro. 1174/1986), y en la STC 197/1990 de 29 de noviembre (Ro. 738/1988). De hecho, los recurrentes calificaron la actuación empresarial como la "trampa saducea tendida por la empresa", pues, "la manifestación expresa de los recurrentes en favor de permanecer en la empresa conllevaba la inclusión en el expediente de otros trabajadores, lo que aparecería ante la plantilla como un privilegio abusivo y entrañaba un desprestigio para el Sindicato, y su silencio se toma como pretexto para despedir".

La primera consideración del TC se refiere al hecho de que se trataba de un comité de empresa sindicalizado, es decir, en el que sus integrantes forman parte de organizaciones sindicales, por lo que estos gozan de una clara protección legal para el ejercicio de sus funciones representativas. De hecho, los representantes recurrentes eran todos afiliados al sindicato CCOO, y accedieron al comité de empresa por la candidatura que dicho sindicato presentó en las elecciones. De hecho, la STC 40/1985 de 13 de marzo (Ro. 397/1984) reconoce que las garantías y facilidades de que gozan los representantes de los trabajadores "se incorporan al contenido esencial del derecho de libertad sindical", en particular cuando se está ante un comité de empresa sindicalizado, lo cual es muy habitual en el modelo español de relaciones laborales.

La interpretación realizada por la empresa, según la cual puede incluir a los representantes de los trabajadores entre los afectados por el despido, y exigirles que expresen si desean ejercitar su

\footnotetext{
${ }^{15}$ Desde la reforma laboral de 2012, ya no existe ninguna autorización administrativa previa al despido colectivo. Sobre la supresión de la autorización administrativa en los despidos colectivos, véase PUEBLA PINILLA, Ana de la, Las paradojas del despido colectivo tras la supresión de la autorización administrativa. Teoría y Derecho: revista de pensamiento crítico. España, Tirant lo Blanch, núm. 13, 2013, p. 129-156.
} 
garantía, admitiendo el silencio al respecto como una renuncia tácita a la misma, supone interpretar de la manera más restrictiva posible la mencionada garantía. De hecho, para el TC, dicho planteamiento coloca "a los titulares del derecho en la situación límite de: o renunciar al mismo, para beneficiar a otros trabajadores sin representación alguna, o no renunciar, con perjuicio de ellos".

La STC 191/1996 de 26 de noviembre cuenta, no obstante, con un Voto particular formulado por el Magistrado don Pedro Cruz Villalón, en el que considera que no ha habido vulneración de la libertad sindical. En este sentido, señala que "la cuestión debe ser siempre reconducida a lo que es su extremo relevante, es decir, si los representantes fueron privados de su derecho a permanecer prioritariamente en la empresa", y considera que es innegable que los representantes han tenido la opción de ejercitar la garantía de prioridad de permanencia.

En definitiva, el destacado pronunciamiento de la STC 191/1996 de 26 de noviembre precisa el alcance de la prioridad de permanencia, en particular respecto de los representantes legales de los trabajadores que han sido elegidos en tanto que integrantes por una lista presentada por un sindicato. Ello conlleva que la cuestión incida en el derecho fundamental a la libertad sindical del art. 28.1 CE. Para el TC, en conclusión, la inclusión de los representantes de los trabajadores en los planes iniciales del empresario vulneraba el derecho fundamental a la libertad sindical y el Convenio de la OIT núm. 135, sobre los representantes de los trabajadores. ${ }^{16}$ Por lo tanto, aunque en el asunto discutido se reconocía a los representantes incluidos la posibilidad de "ejercitar" la garantía de prioridad de permanencia, su inclusión en los planes iniciales del empresario implicaba que el ejercicio de dicha garantía supusiese la inclusión en los planes de despido de otro trabajador inicialmente no afectado, que sustituyera al representante de los trabajadores. De dicho modo, se colocaba a los representantes ante una disyuntiva de difícil solución y que ponía en juego su propia inclusión en los planes de despido o la de otros trabajadores cuyos intereses representaban y tenían la obligación de defender. Por lo tanto, la inclusión sin más de dichos representantes miembros de un sindicato, y además sin justificar dicha inclusión, atenta contra la libertad sindical. ${ }^{17}$

Pronunciamientos posteriores han confirmado esta interpretación. En este sentido, la SAN de 12 de junio de 2013 (Procedimiento núm. 143/2013) considera también una vulneración de la libertad sindical que se coloque a los representantes ante una "disyuntiva imposible", como es la de imponer el despido de trabajadores no inicialmente afectados a cambio de salvar sus puestos de trabajo. Precisamente esta es una cuestión relevante, pues los propios representantes participan en el período de consultas de una reestructuración en la que ellos mismos podrían verse afectados. La garantía pretende que los representantes no estén condicionados por su posible afectación.

Todo ello demuestra que el juego de las reglas de preferencia entre los representantes que disfrutan de esta garantía y los trabajadores concurrentes para verse afectados puede generar tensiones en el seno de la plantilla. De este modo, la inicial inclusión en el listado de afectados de trabajadores que ostenten la condición de representantes de los trabajadores coloca a dichos representantes en la "tesitura" de pedir su exclusión de la lista de afectados para afectar a otro trabajador, o de permanecer en la lista y verse afectado uno mismo. Es decir, el representante debe elegir entre hacer valer su garantía de prioridad de permanencia afectando a otro trabajador, o renunciar a su garantía de permanencia viéndose él mismo afectado por el despido.

\footnotetext{
${ }^{16}$ Convenio de la OIT núm. 135, sobre los representantes de los trabajadores, de 1971 (C135).

${ }^{17} \mathrm{Al}$ respecto, BLASCO PELLICER, Los expedientes de regulación de empleo, ob. cit., p. 113.
} 


\section{3. Ámbito de afectación de la garantía}

El ámbito de afectación o alcance de la prioridad de permanencia de los representantes de los trabajadores tiene una estrecha vinculación con otros conceptos que se van a explicar a continuación, y que no son otros que la lógica de la sustitución, el ámbito de la causa del despido, el ámbito de la representación, y el ámbito funcional del puesto ocupado por el titular de la garantía.

El alcance de la garantía de permanencia en la empresa plantea numerosos interrogantes que la convierten en una cuestión harto compleja sobre la que se han pronunciado los tribunales ante la evidente indefinición del marco normativo. Cabe destacar la SAN de 12 de junio de 2013 (Procedimiento núm. 143/2013), posteriormente confirmada por la STS de 21 de octubre de 2014 (Ro. 59/2014, Sala de lo Social), que hace un recorrido por toda la doctrina en la materia.

En este sentido, cabe destacar la STSJ de Cataluña, de 22 de enero de 2013 (Rº. 6055/2012), con referencia a la STS de 30 de noviembre de 2005 (Ro. 1439/2004, Sala de lo Social), que define la prioridad de permanencia como el "reconocimiento de una preferencia de conservación del empleo", y recuerda que la normativa no fija el ámbito al que dicha garantía se extiende, con la consecuente problemática y casuística generada. Destaca que la garantía es "relativa", lo que significa que "no puede actuar cuando desaparecen todos los puestos de trabajo". La clave es que la desaparición de todos los puestos de trabajo implica la imposibilidad de efectuar una "alternativa de selección", es decir, elegir entre qué trabajadores se prefiere. Es por ello que dicha posibilidad de seleccionar de modo alternativo a un trabajador u otro sólo existe cuando hay "varios puestos de trabajo sobre los que se proyecta el efecto de la causa extintiva". ${ }^{18}$

En definitiva, la garantía de prioridad de permanencia operará cuando existan varios puestos de trabajo sobre los que realizar una alternativa de selección. A continuación se analizan los distintos parámetros a valorar.

\subsection{La lógica de la sustitución y su alcance}

La operatividad de la garantía de prioridad de permanencia implica un potencial perjuicio para otros trabajadores que en principio podrían no haber estado afectados por el despido colectivo, en lo que el TS califica como "lógica de la sustitución". ${ }^{19}$ De este modo, un trabajador inicialmente no afectado por el despido puede verse afectado si su puesto resulta asignado al representante de los trabajadores en aplicación de la regla de prioridad de permanencia, lo que, en caso de no existir otra vacante, resultaría finalmente en la afectación del trabajador no priorizado. Ahora bien, es de destacar, y así lo señala el TS, que esta "lógica de la sustitución" es consecuencia de la efectividad de la garantía misma, y que tiene lugar en cualquier caso, ya que una regla de prioridad de permanencia siempre va a implicar, con carácter general, un "sacrificio potencial" para otros trabajadores ocupados dentro del alcance de la garantía pero no beneficiados por la misma.

El no reconocimiento de la lógica de la sustitución en la garantía de permanencia podría poner en riesgo la efectividad de la misma, ya que el empresario podría acudir a sus facultades relativas a la movilidad funcional para soslayarla, por ejemplo asignando a los trabajadores que desee despedir a la unidad productiva afectada por el despido. Es por ello que los tribunales han reconocido la lógica de la sustitución de la regla de prioridad de permanencia de los representantes de los trabajadores, es decir, que la regla es capaz de producir un perjuicio en otro trabajador.

\footnotetext{
${ }^{18}$ En estos términos, BLASCO PELLICER, Ángel Antonio, La extinción del contrato de trabajo en la reforma laboral de 2012. València, Tirant lo Blanch, 2013, p. 81.

${ }^{19}$ Véase STS de 30 de noviembre de 2005 (Ro. 1439/2004, Sala de lo Social).
} 


\subsubsection{Primeras interpretaciones restrictivas}

No obstante, en los primeros años tras la aprobación del ET de 1980, hubo algún pronunciamiento judicial que acogía una interpretación restrictiva del alcance de la garantía de prioridad de permanencia, y que ya en su momento fue rechazado por la doctrina. ${ }^{20}$ Así, la STS de 11 de junio de 1984 (RJ 3190, Sala de lo Contencioso-Administrativo) señaló que el "beneficio" de prioridad de permanencia es un derecho que "habrá de venir condicionado por la actividad o acción del trabajador en el ejercicio de su representación", por lo que, ante causas empresariales que motiven el despido (las entonces llamadas causas económicas o tecnológicas) y que sean "ajenas" a la actividad representativa, "es claro que no tiene razón de subsistencia ni de privilegiada continuidad el mencionado beneficio”.

Dicha interpretación sorprendentemente restrictiva se realiza, a modo de ver del que suscribe, contra legem, pues el tenor literal del art. 68 b) ET es (y era) muy claro al establecer una garantía de permanencia en supuestos de despido por causas empresariales, al margen de la actividad representativa. Con dicha interpretación, la Sala de lo Contencioso-Administrativo del TS confundía la garantía de prioridad de permanencia -la cual opera por ella misma otorgando al representante el "beneficio" de permanecer prioritariamente frente al resto de empleados en supuestos de despidos por causas empresariales - con otra garantía, que es la referida a no ser despedido con motivo del ejercicio de su actividad representativa, contemplada en el art. 68 c) ET. Si por el mero hecho de concurrir causas económicas o empresariales, no vinculadas con las funciones representativas, pudiera afectarse a los representantes legales de los trabajadores en el despido colectivo, la garantía de prioridad de permanencia perdería su contenido y su virtualidad.

En este sentido, dicha interpretación equivale a equiparar la prioridad de permanencia con una mera prohibición de despedir por razón del ejercicio de funciones representativas, lo cual se enmarcaría dentro de la garantía de indemnidad. La prioridad de permanencia, en cambio, implica algo más, pues supone una tutela preventiva, que impide la afectación, en línea de principio, de los representantes de los trabajadores, a fin de proteger el ejercicio de sus funciones, y en su caso, su actividad sindical. Dicha interpretación restrictiva fue pronto rechazada por toda la doctrina y por posteriores pronunciamientos judiciales que asumen plenamente la operatividad de la garantía conforme a la comentada lógica de la sustitución, como ejemplifican, por todas, la STS de 6 de mayo de 2003 (Ro. 7034/1998, Sala de lo Contencioso-Administrativo), y la STS de 3 de febrero de 2009 (Ro. 101/2006, Sala de lo Social), anteriormente citadas.

\subsubsection{El ámbito de afectación de la causa del despido y el ámbito de la representación}

La lógica de la sustitución plantea en qué marco puede realizarse dicha sustitución, es decir, en qué casos podrá verse afectado otro trabajador por aplicación de la prioridad sobre el titular de la misma. Ello conduce a comentar dos aspectos: el ámbito de la causa del despido, y, en conexión con ello, el ámbito de la representación del representante.

En cuanto a la causa del despido, desde un punto de vista lógico, cabría pensar que la garantía de prioridad de permanencia se extiende, exclusivamente, al ámbito de afectación del despido colectivo. En este sentido, si el despido colectivo tiene como ámbito de afectación un determinado departamento, unidad productiva, o centro de trabajo, lo lógico sería que fuera en dicho ámbito en el que se proyectase la garantía; mientras que si el ámbito de afectación del despido fuese la empresa

${ }^{20}$ Véase en este sentido, ALBIOL MONTESINOS, Extinción del contrato de trabajo por causas económicas o tecnológicas, ob. cit., p. 330 . 
en su totalidad -por ejemplo por causas económicas de alcance general-, entonces sería la empresa el ámbito donde operaría la garantía. Ahora bien, dicha interpretación lógica llevaría a dejar desprotegidos a los representantes de los trabajadores en varios supuestos, de modo que la garantía de prioridad de permanencia quedaría vaciada de contenido y sería ineficaz. Así, en los supuestos en que el ámbito de afectación de las causas de despido no alcanzase a toda la empresa, sino al centro, unidad o departamento donde el representante preste servicios, éste podría verse más fácilmente afectado por el despido.

En consecuencia, tanto la doctrina como los tribunales han señalado que la operatividad de la garantía, y por tanto de la lógica de la sustitución, se produce en un marco que puede ser superior al del ámbito de afectación de la causa del despido colectivo. De hecho, no hay ninguna norma que circunscriba el ámbito de operatividad de la garantía al ámbito de afectación de la causa extintiva en el despido colectivo. El art. 68 b) ET únicamente indica que la prioridad de permanencia operará "respecto de los demás trabajadores", y habría que añadir demás trabajadores "de la empresa".

En este sentido, hay cierto consenso en que la garantía se extiende "más allá del ámbito de afectación del despido colectivo", ${ }^{21}$ no quedando circunscrita sólo al ámbito de afectación del despido colectivo o del concreto puesto de trabajo que ocupa el representante.

Precisamente, la STS de 30 de noviembre de 2005 (Ro. 1439/2004, Sala de lo Social) aborda la cuestión del alcance de la garantía de prioridad de permanencia, señalando que no hay motivo para pensar que la mencionada garantía deba quedar circunscrita al estricto ámbito de afectación de la causa de despido alegada. De hecho, el propio art. 68 b) ET señala que la garantía opera "en la empresa o centro de trabajo". El TS señala que dicha referencia a la empresa o centro de trabajo implica una conexión con el siguiente concepto a comentar: el ámbito de representación que ostenta el representante de los trabajadores. ${ }^{22}$

De este modo, el TS considera que si el ámbito de representación del trabajador es el de toda la empresa, la garantía deberá extenderse al ámbito de la empresa en su totalidad; y, del mismo modo, si el ámbito de representación del trabajador se circunscribe al centro de trabajo, la garantía se limitará a dicho ámbito: el centro de trabajo. La mención alternativa del art. 68 b) ET, referida a "la empresa o centro de trabajo", se refiere pues al ámbito de representación que ostente el representante, que es al cual habrá de ceńirse la garantía, ${ }^{23}$ y ello con independencia del ámbito de afectación de la causa del despido.

Así lo señala también la doctrina de los TSJ, como por ejemplo la STSJ de Galicia, de 9 de julio de 2012 (Ro. 2021/2012), al afirmar que "no hay ninguna regla que establezca que la garantía de la preferencia deba quedar limitada al ámbito de afectación de la causa extintiva sino que, por el contrario, los preceptos legales citados señalan que la conservación del puesto de trabajo que resulta de la aplicación de la preferencia se extiende a la empresa o al centro de trabajo y éste será en principio el ámbito de afectación".

La operatividad de la garantía de prioridad de permanencia implica, pues, una lógica de la sustitución que va más allá del ámbito de afectación de la causa del despido colectivo y que conecta con el ámbito de la representación del titular de la garantía.

\footnotetext{
${ }^{21}$ Así, véase por todos, CERVERA SOTO, CID BABARRO, El despido colectivo: claves prácticas y análisis jurisprudencial, ob. cit., p. 189.

${ }^{22}$ Sobre esta cuestión, véase ÁLVAREZ ALONSO, Diego, Representación y participación de los trabajadores en la empresa: estudio de jurisprudencia y perspectivas de futuro. València, Tirant lo Blanch, 2020, p. 86.

${ }^{23}$ Véase BLASCO PELLICER, Ángel Antonio, TALÉNS VISCONTI, Eduardo E., La forma y el procedimiento del despido. València, Tirant lo Blanch, 2018, p. 180. También, ALBIOL MONTESINOS, Extinción del contrato de trabajo por causas económicas o tecnológicas, ob. cit., p. 331, quien señala que en tanto que el comité de empresa representa los intereses del conjunto de trabajadores de la empresa, y habiendo secciones o departamentos de la empresa que no se vean afectadas por el despido, todos los miembros del comité deben ser excluidos de los despidos.
} 
Para profundizar más en la cuestión del ámbito de representación de los representantes titulares de la garantía, debe señalarse que si el ámbito de representación del representante se extiende a toda la empresa, la prioridad de permanencia opera también dentro de dicho ámbito; mientras que si el ámbito de representación del representante se limita al centro de trabajo, la prioridad de permanencia quedará circunscrita al mismo, tal y como señala la citada STS de 30 de noviembre de $2005 .{ }^{24}$ Precisamente en dicha sentencia se aborda el supuesto de un despido objetivo por cierre de un centro de trabajo, en el que el Tribunal apreció que la garantía debía extenderse al ámbito de la empresa en tanto que dicho era el ámbito de representación del titular de la garantía. En este sentido, la sentencia señala que "el problema a decidir se plantea en [...] si afectando la causa extintiva a todos los trabajadores de un ámbito determinado de la empresa -sección o estación de servicio-, la garantía de permanencia queda agotada por esa afectación total en el ámbito, o debe ampliarse a otros ámbitos a los que se extienda la representación de los actores", a lo que responde afirmativamente.

Por lo tanto, cuando el ámbito de representación del cargo que ostenta el representante se extiende más allá del ámbito de afectación (cerrado) de la causa, por ejemplo porque se extiende a toda la empresa, será éste -el de la empresa- el ámbito en el que opere la garantía de prioridad de permanencia. En los supuestos en que el ámbito de afectación de las causas del despido sea abierto o general, es decir, que afecte a toda la empresa, esta problemática no se plantea, porque es evidente que la garantía tendrá plena operatividad. ${ }^{25}$

Así lo han confirmado varias sentencias en sede de TSJ. La STSJ de Madrid, de 4 de mayo de 2007 (Ro. 819/2007) señala expresamente que si el ámbito de representación se extiende a la empresa, "dentro de ésta deberá operar la garantía, mientras que si se trata del centro de trabajo, tendrá que limitarse a éste". ${ }^{26}$

Por el contrario, cuando el ámbito de representación del cargo que ostenta el representante se limita al centro de trabajo y coincide -o no- con el ámbito de afectación (cerrado) de la causa, la garantía limita su operatividad a dicho ámbito de representación, es decir, el del centro de trabajo. Ello se traduce en la necesaria afectación del representante de los trabajadores en los supuestos de cierre total del centro de trabajo, cuando su representación se circunscribe a dicho ámbito. Así lo han señalado varias sentencias, como la STSJ de Galicia, de 19 de octubre de 2016 (Ro. 1924/2016), que citando la doctrina de la STS de 30 de noviembre de 2005, señala que "la garantía de permanencia se conecta con el ámbito de representación del trabajador, de modo que si en el caso de autos la representación de la trabajadora se extendía únicamente al centro de trabajo de Lugo, la garantía ha de limitarse a éste".

\subsection{3. Ámbito funcional del puesto ocupado por el titular de la garantía}

Una vez comentado el alcance de la citada lógica de la sustitución, hay que señalar que la concurrencia de dos puestos de trabajo sobre los que aplicar la garantía de prioridad de permanencia parte del presupuesto de que dichos puestos sean funcionalmente equivalentes, es decir, cuando los trabajadores concurrentes realizan las mismas funciones, o bien cuando realizan funciones homo-

\footnotetext{
${ }^{24}$ Así lo señala en la doctrina, BLASCO PELLICER, Los expedientes de regulación de empleo, ob. cit., p. 114. En los mismos términos se pronuncia la SAN de 12 de junio de 2013 (Procedimiento núm. 143/2013), y la STSJ de Madrid, de 12 de marzo de 2012 (Ro. 823/2012).

${ }^{25}$ Así lo señala expresamente la STS de 30 de noviembre de 2005 (Ro. 1439/2004, Sala de lo Social): "Este problema se presenta en ámbitos de afectación 'cerrados', como los que contemplan las sentencias comparadas, pues en los ámbitos 'abiertos' la capacidad de selección no queda acotada de esta forma y puede proyectarse en unidades más amplias incluida la empresa en su conjunto.”

${ }^{26}$ También otras, como la STSJ de Castilla y León (Burgos), de 8 de noviembre de 2012 (Ro. 659/2012); y la STSJ de Cataluńa, de 1 de abril de 2011 (Ro. 7089/2010).
} 
géneas. Sólo en esos casos es viable la lógica de la sustitución de la que se viene comentando en este apartado.

Es decir, no tendría ninguna lógica y supondría un perjuicio para la empresa aplicar la prioridad en la afectación respecto de dos trabajadores cuyos puestos o funciones fueran totalmente diferentes. Por ello, la prioridad entra en juego respecto de dos o más trabajadores que desempeñan las mismas funciones o bien funciones equivalentes.

En consecuencia, siempre que exista idoneidad del trabajador para desempeñar las funciones del puesto asignado, la empresa puede acudir también a sus facultades en cuanto a la movilidad funcional a fin de dar aplicación a la garantía de prioridad de permanencia, en tanto que a través de la misma se pretende garantizar el desempeño de las funciones representativas y, también, el ejercicio del derecho fundamental a la libertad sindical en casos de órganos sindicalizados, el cual debe prevalecer. ${ }^{27}$ Además, el incremento del margen de flexibilidad empresarial en torno a la movilidad funcional operado tras la reforma laboral de 2012, con la supresión de las categorías profesionales y dejando el grupo profesional como único parámetro para hacer de la movilidad funcional un mecanismo viable y eficaz, implica un mayor margen de operatividad para la garantía de prioridad de permanencia.

Así, y sintetizando de un modo muy acertado, la STSJ de Galicia, de 9 de julio de 2012 (Ro. 2021/2012) señala que "la preferencia del representante de los trabajadores puede implicar por ello la aplicación de la movilidad funcional con la necesidad de extinguir (o suspender) el contrato de otro trabajador para preservar la permanencia del representante, pues la garantía opera cuando subsiste un puesto equivalente en el que se desempeñen las mismas funciones. Pero se exige que exista idoneidad del titular del derecho de prioridad de permanencia para obtener una ocupación efectiva mediante el ejercicio de las funciones correspondientes." Precisamente en el asunto tratado en dicha sentencia el Tribunal consideró que no era factible que el representante continuase en la empresa y no pudo operar la regla de prioridad de permanencia, y ello "dada la muy diferente naturaleza y cualificación del puesto" en cuestión.

Con anterioridad a la reforma laboral de 2012, cabía plantearse si la referencia en la documentación inicial al número y "categoría” profesional de los trabajadores afectados hacía referencia a la operatividad de la garantía respecto a los trabajadores de la misma categoría profesional que el representante. Dicha interpretación debe ser rechazada, ya que la garantía no está ni estaba restringida a una categoría profesional concreta (en la actualidad, grupo profesional), sino que opera, tal y como dice el art. 68 b) ET, "respecto de los demás trabajadores", sin especificar su clasificación profesional ni el ámbito de afectación del despido. ${ }^{28}$

Ahora bien, no cabe ninguna duda de que el alcance de la garantía de prioridad de permanencia está estrechamente ligado con las características funcionales del puesto afectado, y en relación con ello, los tribunales se han referido al concepto de idoneidad profesional. La STSJ de Cantabria, de 29 de febrero de 2000 (Ro. 290/1999, Sala de lo Contencioso-Administrativo) lo señala afirman-

\footnotetext{
${ }^{27}$ Sobre esta cuestión, véase GOERLICH PESET, José María, Desarrollo y contenido de las consultas, En: AA.VV., Los periodos de consultas (Colección Informes y Estudios, Serie Relaciones Laborales núm. 104), Madrid, Ministerio de Empleo y Seguridad Social, 2014, p. 76-77. De hecho, la SAN de 8 de julio de 2013 (Procedimiento núm. 180/2013) señala que es recomendable simultanear con los mismos interlocutores la negociación sobre el despido colectivo y otras medidas, fundamentalmente de flexibilidad interna, como las suspensiones de contratos, reducciones de jornada, modificación sustancial de las condiciones de trabajo, etc., ya que con ello se consigue reducir los efectos de la flexibilidad externa.

${ }^{28}$ Véase BLASCO PELLICER, Los expedientes de regulación de empleo, ob. cit., p. 114. De hecho, y en línea con lo ya comentado, dicho autor señala que no hay ningún precepto que disponga que la prioridad de permanencia deba circunscribirse al estricto ámbito de la causa del despido colectivo, pues de hecho, el art. 68 b) ET reconoce la prioridad de permanencia "respecto de los demás trabajadores". Por ello, cabe también descartar interpretaciones que circunscriban el ámbito de operatividad de la garantía a la clasificación profesional (grupo, o antiguas categorías) del representante, o a su concreto puesto.
} 
do que la garantía de prioridad de permanencia "implica conceptualmente la concurrencia de dos o más trabajadores para un mismo puesto de trabajo que subsiste, siendo inherente a ella la idoneidad profesional para su desempeño". ${ }^{29}$

El concepto de idoneidad profesional es más amplio que el de grupo profesional, o el de las antiguas categorías profesionales, lo que permite una mayor amplitud a la hora de aplicar la lógica de la sustitución. De hecho, la doctrina ha defendido que la garantía opere o bien con respecto a trabajadores del mismo grupo profesional; ${ }^{30} \mathrm{o}$, más recientemente y de modo más acertado, respecto de trabajadores funcionalmente equivalentes, es decir, que realicen funciones o tareas similares, sin que existan límites vinculados a la pertenencia a un grupo profesional. ${ }^{31}$

Como consecuencia de ello, la prioridad de permanencia opera siempre que el representante pueda ser reubicado funcionalmente como consecuencia de su idoneidad profesional para el puesto concreto, por lo que será necesario estudiar qué posibilidades hay en la empresa, más allá del estricto ámbito de afectación del despido colectivo, y siempre que se esté dentro del ámbito de representación del cargo que ostente el representante, pues es ahí donde tiene sentido la garantía.

Ello va a plantear necesariamente situaciones en que trabajadores que inicialmente no se veían afectados por el despido, es decir, que se encuentran fuera de su marco de afectación inmediato, se vean finalmente afectados debido a la reubicación funcional del representante legal de los trabajadores en cumplimiento de la regla de prioridad de permanencia. Se trata del funcionamiento de la propia lógica de la sustitución. Dicha posibilidad genera cierta suspicacia entre los trabajadores y sus representantes, por lo que cabría plantearse si no sería más adecuado que la operatividad de la garantía se limitase al estricto ámbito de afectación de la causa del despido, cuando dicho ámbito no afecte a toda la empresa, lo cual tampoco parece viable, pues se pondría en riesgo el ejercicio de las funciones representativas en el correspondiente ámbito de representación (por ejemplo, el conjunto de la empresa).

La operatividad de la prioridad de permanencia respecto de trabajadores que desempeñen tareas o funciones equivalentes ha sido confirmada por la STS de 22 de abril de 2003 (Ro. 687/1998, Sala de lo Contencioso-Administrativo), seńalando que la "pluralidad o concurrencia de trabajadores" en el desempeño de "tareas de idéntica o análoga naturaleza" constituye el "requisito imprescindible" para poder ejercitar la garantía.

Es de destacar, para finalizar, la STSJ de Asturias, de 16 de noviembre de 2012 (Ro. 2065/2012), que remarca que la prioridad de permanencia no obliga a la empresa a crear un nuevo puesto de trabajo acorde con la clasificación profesional del representante, ni tampoco a atribuirle funciones distintas a las propias y que supongan una modificación sustancial de las condiciones de trabajo. En el asunto tratado, los únicos puestos a los que podría haber optado el representante pertenecían a un grupo profesional superior con mayor retribución, sin que constase que el representante tuviera capacitación suficiente para el mismo, por lo que no era posible aplicar la prioridad.

En definitiva, la intercambiabilidad funcional de los puestos es necesaria para que opere la garantía de prioridad de permanencia.

\footnotetext{
${ }^{29}$ La misma sentencia continúa señalando: "Incluso han sido tratados por la jurisprudencia supuestos en los que el ejercicio del derecho de permanencia implicaba una movilidad funcional descendente, lo que ha de llevar a la conclusión de que ese derecho de permanencia se produce cuando los puestos que subsisten, son equivalentes, o entre trabajadores que cumplen la misma función."

${ }^{30}$ En este sentido, BLASCO SEGURA, Benjamín, La extinción del contrato por causas tecnológicas o económicas: el expediente de regulación de empleo. Actualidad Laboral. Espańa, Wolters Kluwer, núm. 33, 1992, p. 575-603, en p. 591.

${ }^{31}$ En este sentido, NORES TORRES, Luis Enrique, El periodo de consultas en la reorganización productiva empresarial. Madrid, CES, 2000, p. 261; FERNÁNDEZ DOMÍNGUEZ, Juan José, Expedientes de regulación de empleo. Madrid, Trotta, 1993, p. 190191; y BLASCO PELLICER, Los expedientes de regulación de empleo, ob. cit., p. 115.
} 


\subsection{El carácter relativo de la garantía}

Como corolario de lo anteriormente expuesto, y como se ha anticipado al inicio del epígrafe, existe un cierto consenso entre la doctrina relativo a que la garantía de prioridad de permanencia no opera con carácter absoluto. Ello significa que el representante de los trabajadores no tiene derecho a permanecer en la empresa en cualquier circunstancia, ya que podría suceder que la empresa eliminara todos los puestos de trabajo, o que no existiera un puesto funcionalmente equivalente, por lo que no habría prioridad posible. Por ello, cabe decir que la garantía de prioridad de permanencia tiene un carácter relativo, por lo que debe ponerse en relación con otras circunstancias que pueden darse en el seno de la empresa durante el procedimiento de despido colectivo.

Los tribunales han señalado expresamente que la garantía de prioridad de permanencia no es un derecho "esgrimible con carácter absoluto" erga omnes, es decir, frente a todos los trabajadores en cualquier circunstancia, tal y como indica la STS de 22 de abril de 2003 (Ro. 687/1998, Sala de lo Contencioso-Administrativo), y la STS (3a) de 6 de mayo de 2003 (Ro. 7034/1998, Sala de lo Contencioso-Administrativo), que recuerdan que la prioridad de permanencia es "relativa por su propia esencia”.

Como se ha analizado en el presente epígrafe, existen numerosas manifestaciones del carácter no absoluto, sino relativo, de la garantía. Dichas manifestaciones son, en primer lugar, que la garantía no opera cuando la medida afecta a todos los trabajadores de la empresa (cierre total de la empresa en despidos colectivos, o afectación de todos los trabajadores en supuestos de suspensión de contratos o de movilidad geográfica). Por otro lado, la garantía tampoco opera cuando se procede al cierre total del centro de trabajo en el que presta servicios el representante, si su ámbito de representación se limita al centro de trabajo y no se extiende a la empresa en su conjunto. Finalmente, la garantía de prioridad de permanencia no opera cuando no existen puestos funcionalmente equivalentes, es decir, intercambiables, respecto de los que hacer operar la prioridad.

Se trata de circunstancias que vienen a matizar el alcance de la lógica de la sustitución, ya que ésta no será posible en todos los casos. Precisamente en materia de equivalencia funcional de los puestos, la STSJ de Cataluña, de 24 de julio de 2014 (Ro. 2031/2014) señala que "se trata únicamente de una prioridad, que no de un derecho total y absoluto sobre todos y cada uno de los demás trabajadores de la empresa". En el mismo sentido, la STSJ de Asturias, de 16 de noviembre de 2012 (Ro. 2065/2012) rechazó la posibilidad de aplicar la regla de prioridad de permanencia, pues no existía en la empresa ningún puesto "funcionalmente equivalente" al del representante, indicando que la garantía no puede exigirse "de un modo absoluto", pues, de lo contrario, se llegaría al absurdo de mantener al representante con unas funciones inexistentes.

En síntesis, la lógica de la sustitución se aplica dentro del ámbito de representación del titular de la garantía, con independencia del ámbito de afectación de la causa del despido, pero sometida a unos condicionantes, siendo el principal de ellos que los dos puestos sobre los que se realiza la alternativa de selección sean funcionalmente intercambiables.

\section{La necesaria justificación de la afectación de trabajadores titulares de la garantía de priori- dad de permanencia}

La protección de las funciones representativas, así como la necesaria prevalencia del derecho fundamental a la libertad sindical en supuestos de representación sindicalizada, son aspectos que la garantía pretende salvaguardar. Estos aspectos imponen a la empresa durante el procedimiento de despido colectivo la obligación de expresar las razones que justifiquen la inclusión del representante 
de los trabajadores en la lista de afectados y la privación para el mismo de la garantía recogida legalmente. En definitiva, la empresa deberá justificar su decisión de incluir al representante legal de los trabajadores entre los afectados, a fin de evitar conflictos ante impugnaciones futuras.

La STSJ de Asturias, de 16 de noviembre de 2012 (Ro. 2065/2012), y la SAN de 21 de noviembre de 2012 (Procedimiento núm. 167/2012), señalan expresamente que el representante legal de los trabajadores tiene prioridad de permanencia sobre el resto de trabajadores "salvo que se acredite objetivamente que es su puesto entre los afectados y no otro -sobre el que pueda ejercerse la preferencia- el que se necesita amortizar".

Por ello, el empresario deberá acreditar que concurren razones organizativas o productivas de entidad suficiente como para justificar la exclusión de la garantía y la consiguiente inclusión del representante titular de la garantía entre los afectados por el despido. ${ }^{32}$ En este sentido, el art. 13.3 RPDC señala expresamente que la empresa "deberá justificar en la decisión final de despido colectivo a que se refiere el artículo 12, la afectación de los trabajadores con prioridad de permanencia en la empresa”. De este modo, la inclusión de un representante con prioridad de permanencia es posible, pero debe estar expresamente justificada.

La necesaria justificación de una hipotética afectación de los representantes de los trabajadores en el despido colectivo se refiere tanto a su afectación final (al concluir el período de consultas), como a su afectación inicial (en el escrito de iniciación del procedimiento). Aunque hay que señalar que la afectación de los representantes, debido al alcance de la garantía de prioridad de permanencia, debe ser un supuesto excepcional que esté debidamente justificado por la imposibilidad de mantener al representante en su puesto. Por ello, resulta aconsejable, en la medida de lo posible, no incluir a los representantes entre los afectados, ya que su inclusión va a generar una discusión jurídica en torno al alcance de la garantía y a su operatividad en el caso concreto, además de condicionar las consultas.

Además, la afectación inicial de los representantes, es decir, su inclusión en la solicitud inicial del procedimiento antes de iniciar la negociación propia del período de consultas, y sobre todo en los casos en que dicha afectación no está justificada o lo está de manera parca, genera numerosos problemas. La doctrina por ello se muestra, en línea de principio, contraria a la afectación inicial de los representantes de los trabajadores. ${ }^{33}$

Ahora bien, todo ello no impide, como se ha visto, que los representantes de los trabajadores, a pesar de la garantía de prioridad de permanencia, puedan verse afectados por el despido colectivo, siempre que se haya aplicado la garantía y concluido su no operatividad, de suerte que la selección de dichos trabajadores sea necesaria y, además, esté debidamente justificada. Por ello, el incumplimiento de las reglas de prioridad de permanencia no implica automáticamente una vulneración de las reglas relativas al período de consultas, sino que habrá que comprobar si "concurre efectivamente una actuación empresarial coactiva", lo cual no ocurre si la empresa "flexibilizó desde el primer momento su posición y no bloqueó la negociación”, en los términos expresados por la SAN de 21 de noviembre de 2012 (Procedimiento núm. 167/2012). ${ }^{34}$

\footnotetext{
${ }^{32}$ Sobre esta cuestión, BLASCO PELLICER, Los expedientes de regulación de empleo, ob. cit., p. 115.

${ }^{33}$ Véase BLASCO PELLICER, Los expedientes de regulación de empleo, ob. cit., p. 113. Con anterioridad a la reforma laboral de 2012, señala que la prioridad de permanencia "impide que sean incluidos en la lista de afectados, caso de ser ésta nominativa, o que pudieran serlo", en el supuesto de que se incluyan número y categoría profesional de los afectados. Ahora bien, el mismo autor señala que dicha imposibilidad no es total ni absoluta, por lo que habrá que delimitarla, pues en determinadas circunstancias, y si el empresario lo justifica adecuadamente, los representantes de los trabajadores beneficiarios de la garantía sí que podrían ser incluidos en el despido colectivo. Por su parte, CERVERA SOTO, CID BABARRO, El despido colectivo: claves prácticas y análisis jurisprudencial, ob. cit., p. 147, señala que "los listados iniciales de afectaciones posibles deben respetar la garantía de permanencia" de los representantes legales de los trabajadores.

${ }^{34}$ Véase también SÁEZ LARA, Carmen, Reestructuraciones empresariales y despidos colectivos. València, Tirant lo Blanch, 2015, p. 188.
} 
Por su parte, si bien el presente estudio no entra en las cuestiones procesales, debe tenerse en cuenta que la incorrecta inclusión de los representantes de los trabajadores entre los afectados iniciales no conlleva la nulidad del procedimiento en su conjunto, sino que es objeto de impugnación individual por vía del art. 124.13 de la Ley 36/2011, de 10 de octubre, reguladora de la jurisdicción social (LRJS). ${ }^{35}$

Por otro lado, y en relación con la necesidad de acreditación empresarial del carácter no discriminatorio de la afectación, además de la justificación de la inclusión entre los afectados de un trabajador titular de la mencionada garantía, no hay que olvidar que en estos casos va a producirse la distribución de la carga de la prueba o desplazamiento del onus probandi respecto de las alegaciones que se refieran al carácter discriminatorio o antisindical, y, en suma, vulnerador de los derechos fundamentales del trabajador afectado titular de la garantía. ${ }^{36}$

De este modo, si el trabajador presenta indicios de entidad suficiente como para sospechar de la existencia de una práctica antisindical, discriminatoria o vulneradora de derechos fundamentales, corresponderá a la empresa acreditar las causas que justifiquen la procedente inclusión del trabajador entre los afectados. ${ }^{37}$

La STS de 6 de mayo de 2003 (Ro. 7034/1998, Sala de lo Contencioso-Administrativo), reiterada a su vez por la STS de 18 de marzo de 2009 (Ro. 879/2007, Sala de lo Contencioso-Administrativo), establece que la justificación facilitada por la empresa para incluir al trabajador titular de la garantía en el listado de afectados debe ser "convincente y concreta", señalando las circunstancias y situación particular y organizativa de la empresa que de verdad impidan la aplicación de la garantía de prioridad de permanencia. Por ello, no bastan argumentaciones apriorísticas o basadas en criterios generales de tipo jurídico o económico que se refieran a la imposibilidad en abstracto de dar virtualidad a la prioridad de permanencia, pues de lo contrario se estaría dejando sin efecto la mencionada garantía.

De hecho, la doctrina constitucional establece los requisitos de la justificación que debe dar la empresa respecto de las alegaciones de discriminación y vulneración de derechos fundamentales, y que debe entenderse aplicable a la justificación de la inclusión en el despido de trabajadores con garantía de prioridad de permanencia, a fin de evitar la nulidad del despido. En este sentido, la STC 29/2002 de 11 de febrero (Ro. 198/1998); STC 30/2002 de 11 de febrero (Ro. 1481/1998); y la STC 49/2003 de 17 de marzo (Ro. 988/1999), en materia de vulneración del derecho fundamental a la libertad sindical, señalan que "es exigible una justificación causal de la decisión [de despido] en su específica y singular proyección sobre el caso concreto, explicando objetiva, razonable y proporcionadamente tal decisión y eliminando toda sospecha de que ésta ocultara la lesión de un derecho fundamental de la trabajadora, sin que pueda servir para lograrlo la abstracta razón de legalidad invocada".

\footnotetext{
${ }^{35}$ En materia de nulidad por vulneración de la garantía de prioridad de permanencia, y su remisión a las impugnaciones individuales ex art. 124.13 LRJS, véase la STSJ de Castilla y León (Valladolid), de 9 de diciembre de 2015 (Rº. 1751/2015); STSJ de País Vasco, de 17 de junio de 2014 (Ro. 21/2014); STSJ de Castilla-La Mancha, de 31 de marzo de 2014 (Ro. 62/2014); y la STSJ de Galicia, de 2 de mayo de 2013 (Ro. 10/2013).

${ }^{36}$ Sobre la doctrina constitucional sobre el desplazamiento del onus probandi en supuestos de alegación de discriminación o vulneración de derechos fundamentales en materia laboral, véase la STC 17/2003 de 30 de enero (Ro. 1150/1999), con cita a la STC 90/1997 de 6 de mayo (Ro. 3309/1994); STC 66/2002 de 21 de marzo (Ro. 2331/1998); y la STC 207/2001 de 22 de octubre (Ro. 1515/1998).

${ }^{37}$ En este sentido, la doctrina constitucional contenida en la STC 38/1981 de 23 de noviembre (Ro. 189/1981) señala que "cuando se prueba indiciariamente que la extinción de un contrato de trabajo puede enmascarar una lesión de derechos fundamentales, atańe al empresario acreditar que su decisión obedece a motivos razonables y ajenos a todo propósito atentatorio del derecho de que se trate". En el mismo sentido se pronuncia la STC 49/2003 de 17 de marzo (Rº. 988/1999).
} 


\section{5. Ámbito subjetivo de la regla de prioridad de permanencia ${ }^{38}$}

Como se ha señalado al comienzo del presente estudio, el objeto de investigación se ha centrado principalmente en la configuración de la garantía de prioridad de permanencia a favor de los representantes de los trabajadores. Ello no obsta a que deba señalarse, también, el ámbito subjetivo de dicha garantía, o lo que es lo mismo, a qué sujetos les resulta aplicable, más allá de la figura de los representantes legales de los trabajadores, y en qué momento temporal concreto. Razones de metodología han aconsejado, pues, dejar esta cuestión para el final.

En primer lugar, y de ello no cabe ninguna duda, la prioridad de permanencia beneficia a los representantes legales de los trabajadores, tal y como señala expresamente el art. 51.5 ET y el art. 68 b) ET, así como el art. 13.1 RPDC. Ahora bien, la noción de representante legal de los trabajadores a los efectos del disfrute de la prioridad de permanencia se entiende en un sentido amplio, de suerte que incluye a otros sujetos que también se beneficiarán de la garantía de prioridad de permanencia.

\subsection{Representantes legales de los trabajadores: delegados de personal y miembros del comité de empresa ${ }^{39}$}

Los beneficiarios originarios de la garantía de prioridad de permanencia son los representantes legales de los trabajadores. Como representantes legales de los trabajadores cabe entender, en primer lugar, y según el art. 62.1 ET, a los delegados de personal elegidos en aquellas empresas o centros de trabajo con menos de 50 trabajadores y más de 10, y también a los delegados de personal en empresas o centros de entre 6 y 10 trabajadores cuando estos hayan decidido contar con dicho delegado.

En segundo lugar, en aquellos centros de trabajo que tengan 50 o más trabajadores, la prioridad de permanencia beneficia a los miembros del comité de empresa que se constituya ex art. 63.1 ET, y también en los casos de comité de empresa conjunto en aquellas empresas con varios centros de trabajo que no alcancen de por sí los 50 trabajadores pero los superen en su conjunto (art. 63.2 ET).

En cuanto al comité intercentros, en aquellos casos en que un convenio colectivo prevea su creación, no hay duda de que sus miembros también son beneficiarios de la prioridad de permanencia, pues sus integrantes, según el art. 63.3 ET, son designados de entre los miembros de los comités de centro.

\subsection{Delegados sindicales ex art. 10.3 LOLS}

Como consecuencia del modelo dual de representación de los trabajadores, la prioridad de permanencia también alcanza a otro tipo de representantes de los trabajadores más allá de los que forman

\footnotetext{
${ }^{38}$ Sobre esta cuestión en detalle, véase BLASCO PELLICER, Los expedientes de regulación de empleo, ob. cit., p. 113; y BLASCO PELLICER, La extinción del contrato de trabajo en la reforma laboral de 2012, ob. cit., p. 81.

${ }^{39}$ Sobre la representación legal de los trabajadores en la empresa, véase CASAS BAAMONDE, María Emilia, ESCUDERO RODRÍGUEZ, Ricardo, Representación unitaria y representación sindical en el sistema español de relaciones laborales. Civitas: Revista Española de Derecho del Trabajo. España, Civitas, núm. 17, 1984, p. 51-92; ALBIOL MONTESINOS, Ignacio, Comités de empresa y delegados de personal. Bilbao, Deusto, 1992; ESCUDERO RODRÍGUEZ, Ricardo, MERCADER UGUINA, Jesús Rafael, $M a-$ nual jurídico de los representantes de los trabajadores. Madrid, La Ley, 2004; SÁEZ LARA, Carmen, La representación colectiva de los trabajadores en la empresa. Revista del Ministerio de Trabajo e Inmigración. España, Ministerio de Trabajo e Inmigración, núm. 58, 2005, p. 315-342; y ÁLVAREZ ALONSO, Diego, La representación y participación de los trabajadores en la empresa, a la luz de la Jurisprudencia del Tribunal Supremo. Revista del Ministerio de Empleo y Seguridad Social. España, Ministerio de Empleo y Seguridad Social, núm. 143, 2019, p. 389-430.
} 
parte del esquema principal de representación legal de los trabajadores (delegados de personal y miembros del comité de empresa)..$^{40}$

En consecuencia, la prioridad de permanencia también alcanza a los delegados sindicales que no sean miembros del comité de empresa, ${ }^{41}$ en virtud de lo establecido en el art. 10.3 LOLS. ${ }^{42}$ De hecho, dicho precepto señala expresamente que los delegados sindicales que no formen parte del comité de empresa tendrán las mismas garantías que los miembros del comité de empresa. Además, dicha garantía viene confirmada en el art. 13.1 RPDC. ${ }^{43}$

Por delegados sindicales hay que entender los delegados sindicales "legales", es decir, los contemplados en el art. 10.1 LOLS, según el cual, en empresas o centros que ocupen más de 250 trabajadores, las secciones sindicales que se constituyan conforme a los estatutos del sindicato correspondiente estarán representadas por delegados sindicales elegidos por y entre los afiliados en la empresa o centro.

Cabe destacar que la garantía también se aplica cuando mediante la negociación colectiva se fije una regulación más ventajosa que la legal para obtener delegados sindicales. Así sucede, por ejemplo, en el art. 78 del Convenio colectivo estatal de las empresas de seguridad, ${ }^{44}$ que permite la existencia de delegados sindicales en empresas a partir de 150 trabajadores, ${ }^{45}$ los cuales se beneficiarán de la garantía.

A mayor abundamiento, cuando por convenio colectivo se amplían las garantías de los representantes unitarios, dicha garantía adicional también resulta aplicable a los delegados sindicales que no formen parte del comité de empresa. ${ }^{46}$

\subsection{Delegados de prevención}

La garantía de prioridad de permanencia también alcanza a los delegados de prevención del art. 35 LPRL, es decir, "los representantes de los trabajadores con funciones específicas en materia de prevención de riesgos en el trabajo", como señala el precepto. De hecho, el propio art. 37.1 LPRL les extiende expresamente la aplicación de las garantías del art. 68 ET por su condición de

\footnotetext{
${ }^{40}$ Sobre la representación de los trabajadores, y en particular la representatividad sindical, véase LAHERA FORTEZA, Jesús, Representación y representatividad sindical: puntos críticos y propuesta de reforma. Papeles de economía española. España, Fundación de las Cajas de Ahorro (FUNCAS), núm. 156, 2018, p. 18-27.

${ }^{41} \mathrm{Si}$ fueran miembros del comité de empresa, la garantía les alcanza por su propia condición de representantes legales de los trabajadores ex art. 68 b) ET y 51.5 ET.

${ }^{42}$ Así lo han entendido sin ninguna duda en la doctrina: ALBIOL MONTESINOS, Extinción del contrato de trabajo por causas económicas o tecnológicas, ob. cit., p. 330; ROQUETA BUJ, Remedios, La selección de los trabajadores afectados por los despidos colectivos. València, Tirant lo Blanch, 2015, p. 72; GOERLICH PESET, José María, Los despidos colectivos. Art. 51 ET y normas concordantes, En: BORRAJO DACRUZ, Efrén (dir.), Comentarios a las leyes laborales: la reforma del Estatuto de los Trabajadores. Ley 11/1994, de 19 de mayo, y normas concordantes (Tomo II: el despido), Madrid, Edersa, 1994, p. 174; BLASCO PELLICER, Los expedientes de regulación de empleo, ob. cit., p. 113; y DURÁN LÓPEZ, Federico, Análisis de la regulación jurídico-positiva del despido colectivo en España. Documentación Laboral. España, Cinca, núm. 22, 1987, p. 59-90, en p. 87.

${ }^{43}$ El art. 13.1 RPDC señala: "Conforme a lo establecido en el artículo 51.5 y 68.b) del Estatuto de los Trabajadores y en el artículo 10.3 de la Ley Orgánica 11/1985, de 2 de agosto, de Libertad Sindical, los representantes legales de los trabajadores tendrán prioridad de permanencia en la empresa respecto de los demás trabajadores afectados por el procedimiento de despido colectivo."

${ }^{44}$ Resolución de la Dirección General de Empleo de 19 de enero de 2018, por la que se registra y publica el Convenio colectivo estatal de las empresas de seguridad (BOE 01/02/2018).

${ }^{45}$ Sobre la mejora de los requisitos para nombrar un delegado sindical en el Convenio colectivo estatal de las empresas de seguridad, véase la STS de 24 de octubre de 2017 (Ro. 100/2016, Sala de lo Social), que declaró que cada sección sindical, con independencia de que se hubiera constituido a nivel de centro de trabajo o a nivel de empresa, tenía derecho a nombrar un delegado sindical si la empresa superaba el umbral de 150 trabajadores.

${ }^{46}$ Así lo subraya PALOMO VÉLEZ, Ricardo, El modelo español de representación de los trabajadores en la empresa. València, Tirant lo Blanch, 2017, p. 502.
} 
representantes. ${ }^{47}$ La finalidad de la extensión de la garantía de prioridad de permanencia a los delegados de prevención en estos casos es precisamente proteger sus funciones en materia preventiva. ${ }^{48}$

\subsection{Trabajadores designados por el empresario para ocuparse de tareas de prevención}

Del mismo modo, la garantía del art. 68 b) ET se extiende también a los trabajadores designados por el empresario ex art. 30.1 LPRL para ocuparse de las tareas de prevención, así como a los miembros del servicio de prevención propio creado ex art. 31.1 LPRL. ${ }^{49}$ En este sentido, el art. 30.4 LPRL les extiende ciertas garantías del art. $68 \mathrm{ET}$, entre ellas la prioridad de permanencia del apartado b) del mismo artículo, y seńala expresamente que los trabajadores designados no podrán sufrir ningún perjuicio como consecuencia del ejercicio de sus tareas de prevención.

Así, la STSJ de Asturias, de 20 de diciembre de 2013 (Ro. 1868/2013) confirma la nulidad del despido de un trabajador designado por la empresa para ocuparse de la actividad de prevención, ya que ocupaba el puesto de jefe de prevención, y censura la sentencia de instancia, que le negó la garantía "por entender, erróneamente, que sólo los Delegados de Prevención, esto es, los representantes de los trabajadores con funciones específicas en materia de prevención de riesgos en el trabajo (art. 35 LPRL), tienen ese derecho", cuando lo cierto es que el propio art. 30.4 LPRL reconoce expresamente la garantía para los trabajadores designados por la empresa.

El objetivo de dicha garantía es proteger la independencia de estos trabajadores frente al poder empresarial, extendiéndoles garantías propias de los representantes de los trabajadores, precisamente porque no tienen dicha condición.

La misma STSJ de Asturias, de 20 de diciembre de 2013, reiterando la STSJ de Asturias, de 26 de julio de 2013 (Ro. 1058/2013), señala que la extensión de la garantía de prioridad de permanencia ex art. 30.4 LPRL "alcanza a los trabajadores designados por la empresa y a los trabajadores integrantes del servicio de prevención cuando la empresa decida constituirlo, [...] y esos trabajadores gozan de la misma garantía de prioridad de permanencia que los representantes de los trabajadores."

La consecuencia de despedir a uno de estos trabajadores sin respetar la garantía de prioridad de permanencia es la misma que en los supuestos referidos a representantes legales de los trabajadores: se declara la nulidad del despido ex art. 124.13 LRJS.

Algún pronunciamiento ha exceptuado la prioridad de permanencia de los miembros del servicio de prevención en situaciones específicas. Tal es el caso de la STSJ de la Comunitat Valenciana, de 10 de septiembre de 2013 (Ro. 1481/2013), que señala que dicha prioridad no puede operar en un supuesto en el que la reestructuración se fundamenta, entre otras, en causas organizativas que "afectan de forma específica al servicio de prevención”.

Ahora bien, por su parte, algún pronunciamiento parece haber realizado una interpretación más restrictiva. La STSJ de Illes Balears, de 23 de febrero de 2011 (Ro. 244/2010) niega que la garantía alcance a un trabajador que fue contratado por la empresa como "experto". También señala otra cuestión discutible, y es la relativa a que "tampoco resulta acreditado en autos que la inclusión del actor en el ERE por parte de la empresa tenga relación alguna con el ejercicio de sus tareas de delegado de prevención”. Se trata de una afirmación discutible, pues la garantía opera por sí misma,

\footnotetext{
${ }^{47}$ Art. 37.1 LPRL: “Lo previsto en el artículo 68 del Estatuto de los Trabajadores en materia de garantías será de aplicación a los Delegados de Prevención en su condición de representantes de los trabajadores."

${ }^{48}$ Véase ROQUETA BUJ, La selección de los trabajadores afectados por los despidos colectivos, ob. cit., p. 72.

${ }^{49}$ Sobre la designación de trabajadores encargados de tareas de prevención y sobre la constitución del servicio de prevención, véanse los arts. 11, 12, 14, y 15 del Reglamento de los Servicios de Prevención, aprobado por Real Decreto 39/1997, de 17 de enero (BOE 31/01/1997).
} 
con independencia de que la afectación en el despido colectivo se haya realizado o no con motivo del desempeño de las funciones encomendadas. ${ }^{50}$

Por su parte, la STSJ de Andalucía (Sevilla), de 10 de mayo de 2012 (Ro. 1994/2011) niega la consideración de trabajador designado a estos efectos al denominado "recurso preventivo" del art. 32 bis LPRL. ${ }^{51}$ En este caso, la interpretación se ajusta a lo que marca la ley, pues la sentencia se refería a un trabajador que no ostentaba la condición de delegado de prevención, ni de trabajador designado para ocuparse de las tareas de prevención, ni de miembro del servicio de prevención, por lo que, de acuerdo con el tenor literal de la ley -que limita la extensión de la garantía únicamente a los mencionados colectivos-, no le correspondía ninguna prioridad de permanencia por el hecho de ser recurso preventivo.

\subsection{Miembros de la comisión ad hoc}

La normativa guarda silencio sobre una eventual extensión de la garantía de prioridad de permanencia a los miembros de la comisión negociadora nombrada ad hoc en ausencia de representantes legales de los trabajadores y de acuerdo con las reglas del art. 41.4 ET. En estos supuestos, si bien hay dudas, la mayoría de la doctrina, o bien no se pronuncia al respecto, o bien se inclina por considerar que la garantía no se extiende a ellos. ${ }^{52}$

Alguna sentencia se pronuncia expresamente, como la STSJ de País Vasco, de 30 de septiembre de 2003 (Ro. 1713/2003), que se refiere a un miembro de comisión ad hoc en un despido colectivo, precisamente para negar la aplicación de las garantías "faltando la cualidad de representante en el actor", lo cual no obsta para que los integrantes de la comisión ad hoc se sigan beneficiando de la protección general en materia antidiscriminatoria. ${ }^{53}$

En este sentido, es defendible la consideración de que la garantía no se extiende a los miembros de la comisión ad hoc, y ello por varios motivos. En primer lugar, la norma guarda absoluto silencio al respecto, a diferencia de lo que ocurre con otros sujetos, como los delegados sindicales o los delegados de prevención, para quienes la norma sí que prevé la aplicación extensiva de las garantías de los representantes de los trabajadores. En segundo lugar, el argumento más importante tiene que ver con las funciones que intenta proteger la garantía: la garantía de prioridad de permanencia tiene por objeto proteger a los representantes en el ejercicio de sus funciones representativas $-y$ de sus funciones sindicales para los delegados sindicales, y sus funciones preventivas para los delegados de prevención-, lo cual justifica que la ley les proteja frente a situaciones de despido, ya que ello perjudicaría sus funciones y, por tanto, a los trabajadores. Por tanto, la garantía, al contemplar la

${ }^{50}$ En este sentido, la STSJ de Illes Balears, de 23 de febrero de 2011 (Ro. 244/2010) cita la STSJ de Islas Canarias (Las Palmas), de 30 de enero de 2004 (Ro. 1664/2003), que adopta un interpretación restrictiva señalando que "incluso la doctrina estima que es excesivo igualar a estos trabajadores que tienen una relación laboral común, con los representantes legales y sindicales de los trabajadores, pues estos últimos actúan en representación de quien los ha nombrado y por ello debe garantizarse su independencia respecto al patrono, mientras que los trabajadores que forman parte del Servicio de Prevención realizan las funciones que les encomienda el empresario para cumplir su ineludible obligación de prevención, deber de cuyo cumplimiento sólo el empresario es responsable".

${ }^{51}$ Art. 32 bis LPRL, ap. 4: "No obstante lo seńalado en los apartados anteriores, el empresario podrá asignar la presencia de forma expresa a uno o varios trabajadores de la empresa que, sin formar parte del servicio de prevención propio ni ser trabajadores designados, reúnan los conocimientos, la cualificación y la experiencia necesarios en las actividades o procesos a que se refiere el apartado 1 y cuenten con la formación preventiva correspondiente, como mínimo, a las funciones del nivel básico.”

${ }^{52}$ En este sentido, GONI SEIN, José Luis, El nuevo modelo normativo de despido colectivo implantado por la Ley de reforma laboral de 2012. Documentación laboral. España, Cinca, núm. 95-96, 2012, p. 25-56, en p. 47.

${ }^{53}$ En este sentido se pronuncia expresamente NIETO ROJAS, Patricia, Comisiones ad hoc y procesos de reorganización productiva empresarial. Una solución legal para empresas sin representación legal de los trabajadores, En: ESCUDERO RODRÍGUEZ, Ricardo (ed.), La negociación colectiva en las reformas de 2010, 2011 y 2012, Madrid, Cinca, 2012, p. 78; mostrándose además a favor de extender dichas garantías a los miembros de la comisión ad hoc, en la medida necesaria para ejercer su función. 
prioridad de permanencia, pretende proteger las funciones representativas del representante con vistas a futuro, es decir, una vez finalizado el procedimiento de despido colectivo, a fin de que pueda continuar desempeñándolas.

Pues bien, en el caso de los miembros de la comisión ad hoc, este tipo de funciones no se da, ya que se está ante sujetos que intervienen en las negociaciones del despido colectivo, pero no ejercen ninguna función que la legislación considere que deba proteger con una proyección más allá de la finalización del procedimiento de despido colectivo, pues se tratará de trabajadores comunes, que no ejercen ninguna función representativa por la que merezcan una especial garantía frente al resto de trabajadores. En cualquier caso, si fueran despedidos como consecuencia de su actuación durante el procedimiento de despido colectivo, contarían con la tutela correspondiente en materia de no discriminación y de garantía de indemnidad.

\subsection{Vigencia del mandato del representante}

Los beneficiarios de la garantía de prioridad de permanencia son los representantes de los trabajadores, con las concreciones realizadas en el apartado anterior. Por esa razón, resulta exigible que el mandato del representante se encuentre en vigor para que opere la garantía. Aun así, se han planteado algunos interrogantes respecto al momento de inicio y finalización del mandato.

\subsubsection{Candidatos proclamados pero no electos}

En primer lugar, por lo que respecta al momento inicial de la vigencia, cabe comentar la figura de los candidatos proclamados pero no electos. Alguna sentencia ha reconocido la extensión de la garantía de prioridad de permanencia a quienes no sean representantes de los trabajadores, pero sí sean candidatos proclamados. Tal es el caso de la STSJ de Galicia, de 21 de julio de 1995 (Ro. 2568/1995), que, a pesar de que la ley no extiende expresamente las garantías de los representantes a los candidatos, considera que se trata de una laguna jurídica que es necesario cubrir. En su argumentación, cita la Recomendación de la OIT núm. 143, sobre los representantes de los trabajadores (1971), que en el apartado 7 alude a la extensión a los candidatos -y a quienes hayan sido presentados como candidatos- de las garantías de que gozan los representantes de los trabajadores.

Dicho argumento es discutible, pues el apartado 7 de la Recomendación se refiere a extender a los candidatos la garantía del apartado 5 de la misma, que es la relativa a la prohibición de despido por razón de su cargo o actividad. La prioridad de "continuación en el empleo" en supuestos de reducción de personal se reconoce, en cambio, en el apartado 6 de la Recomendación, que no hace ninguna referencia a los candidatos.

En cambio, sí que se encuentran pronunciamientos del TS que reconocen las garantías de los apartados a) (apertura de expediente contradictorio) y c) (prohibición de despido) del art. 68 ET a los candidatos, como ejemplifican la STS de 20 de noviembre de 1990 (Ro. 3611/1987, Sala de lo Social), y la STS de 18 de febrero de 1997 (Ro. 1868/1996, Sala de lo Social).

Pero volviendo a la garantía de prioridad de permanencia, es decir, la del apartado b) del art. 68 ET, hay numerosas sentencias dictadas en sede de TSJ que niegan la prioridad de permanencia a los candidatos, no habiendo ningún pronunciamiento expreso del TS.

En este sentido, la STSJ de Cataluńa, de 23 de septiembre de 2010 (Ro. 3367/2010) niega la aplicación de la garantía de prioridad de permanencia a un trabajador precisamente por el hecho de que todavía no era candidato en el momento del despido, ya que la candidatura fue presentada inme- 
diatamente después del momento de ser despedido. Con ello parece presuponer que los candidatos proclamados sí que se beneficiarían de la garantía de prioridad de permanencia. Al respecto, la argumentación gira en torno a la STS de 2 de diciembre de 2005 ( $\mathrm{R}^{\circ}$. 6380/2003, Sala de lo Social), que cita más sentencias como la STS de 20 de junio de 2000 (Ro. 3407/1999, Sala de lo Social) y la STS de 22 de diciembre de 1989 (RJ 9258, Sala de lo Social). Estas reconocen a los candidatos la consideración de representantes de los trabajadores a los efectos de reconocerles el derecho de opción entre la readmisión y la extinción indemnizada del art. 56.4 ET en casos de despido declarado improcedente.

Dicha garantía relativa al derecho de opción se extiende, además, bajo determinadas condiciones, a saber: que el procedimiento electoral esté iniciado, que la empresa conozca la candidatura del trabajador y, además, que el mismo resulte elegido tras el cese. Dicha doctrina ha sido confirmada por pronunciamientos más recientes, como la STS de 28 de diciembre de 2010 (Ro. 1596/2010, Sala de lo Social) y la STS de 22 de febrero de 2018 (Ro. 823/2016, Sala de lo Social). ${ }^{54}$ Esta interpretación referida, como se ha señalado, al derecho de opción en casos de despido declarado improcedente, no es aplicable a la garantía de prioridad de permanencia del art. 68 b) ET.

En este sentido, se encuentran pronunciamientos que con acertado criterio niegan la aplicación de la garantía de prioridad de permanencia a los candidatos (no electos) a elecciones de representantes de los trabajadores. La STSJ de Castilla y León, de 11 de julio de 1995 (Ro. 1382/1995) señala que "es indiferente [...] que determinados trabajadores hayan sido candidatos de un determinado sindicato para las elecciones en la empresa demandada, pues lo único que se protege [...] es a los trabajadores electos y no a los que no lo fueron”. Por ello, deniega la aplicación de la garantía, pues "ninguno de los demandantes reúne la condición de Miembro del Comité de Empresa o Delegado Sindical, ni ha resultado elegido para esos cargos, ni como titular, ni como suplente". ${ }^{55}$

Numerosos pronunciamientos posteriores han seguido dicha interpretación: la garantía sólo alcanza a los representantes de los trabajadores desde el momento en el que resulten electos, con independencia de que hayan o no tomado posesión y empezado a ejercer su cargo, y no desde el momento en que fueron proclamados candidatos y no han sido todavía elegidos. La garantía de prioridad de permanencia pretende proteger la representatividad misma de los cargos, por lo que no resulta aplicable en el caso de los candidatos. En este sentido se pronuncia la STSJ de Andalucía (Granada), de 4 de mayo de 2011 ( $\mathrm{R}^{\mathrm{o}}$. 631/2011), que niega la prioridad de permanencia a un candidato no electo; y también la STSJ de Islas Canarias (Las Palmas), de 18 de diciembre de 2014 ( $\mathrm{R}^{\circ}$. 416/2014), que en un sentido similar señala que "el actor no es representante unitario de los trabajadores, ni delegado sindical ad extra [es decir, ex art. 10.3 LOLS], y tampoco su concurrencia al proceso electoral en el que no fue elegido fue coetánea al despido, de manera que, al mismo no le son aplicables las garantías que para los representantes legales y sindicales de los trabajadores, y por extensión a los candidatos en el proceso electoral que resultasen electos después de su cese, contemplan los arts. 68.1 b), 52 c) y 56.4 ET."

La referencia "y por extensión a los candidatos en el proceso electoral que resultasen electos después de su cese" resulta enigmática, pues introduce la duda de si la garantía de prioridad de permanencia en la empresa sería aplicable a candidatos que resultasen electos tras su cese, lo cual debe descartarse. No parece desprenderse ello del tenor legal de los preceptos correspondientes, además de los pronunciamientos de los tribunales que niegan la garantía a los candidatos en general, pues

\footnotetext{
${ }^{54}$ Por su parte, la STS de 25 de junio de 2012 (Ro. 2370/2011, Sala de lo Social) deniega la extensión de la garantía de opción entre readmisión e indemnización a un trabajador que presentó su candidatura horas después de ser despedido y sin que la empresa tuviese conocimiento de la intención del trabajador de presentarse.

${ }_{55}$ Precisamente, la STS de 15 de marzo de 1993 (Ro. 2788/1991, Sala de lo Social), y una vez finalizado el proceso electoral, niega la aplicación de la garantía del apartado a) del art. 68 ET (apertura de expediente contradictorio) a un trabajador que figuraba como suplente, por no tener la condición de representante.
} 
todavía no han adquirido la condición de representantes que les hace titulares de la misma. Además, una vez cesados, dichos candidatos ya no serían trabajadores de la empresa y no podrían ser representantes, con lo que la única garantía relevante en estos casos sería la ya señalada al derecho de opción en supuestos de despido declarado improcedente.

Un acertado resumen de estas cuestiones se encuentra en la STSJ de Galicia, de 28 de septiembre de 2012 (Ro. 2183/2012), que cita la STSJ de Galicia, de 16 de julio de 2012 (Ro. 1894/2012), que señala que "al candidato formal no le son trasladables de forma automática todas las garantías que el art. 68 del ET reconoce al representante de los trabajadores, sino que ha de estarse necesariamente al caso concreto". A este respecto, cita la mencionada doctrina del TS relativa al derecho de opción en casos de despido declarado improcedente, y destaca "que tal opción no se le reconoce al candidato de una forma automática, sino que se le reconoce tal garantía cuando fueron despedidos apresuradamente días antes de las elecciones, sin base alguna para ello, y siendo elegidos en dichas elecciones, y básicamente para evitar que la conducta empresarial suponga un fraude de ley tendente a evitar el acceso a la condición de representantes de quienes fueron elegidos en elecciones regularmente celebradas". Es decir, la extensión a los candidatos de la garantía del derecho de opción en supuestos de despido declarado improcedente, se aplica en supuestos en que se aprecia una posible motivación discriminatoria por parte del empresario o un fraude de ley, a fin de poner al candidato fuera de la empresa antes de que adquiera la condición de representante.

Por lo tanto, los candidatos no se benefician de la garantía de prioridad de permanencia en la empresa, pero sí que les resulta plenamente aplicable -como no podía ser de otro modo- la tutela antidiscriminatoria por motivo de su actividad sindical. Así lo señaló expresamente la STC 38/1981 de 23 de diciembre ( ${ }^{\circ}$. 189/1981), en el sentido que "la no inclusión en la literalidad de los preceptos reguladores actualmente de las garantías sindicales de aquellos que son candidatos, o que han sido presentados como candidatos a la elección o al nombramiento de representantes de los trabajadores, no es obstáculo a la protección frente a despidos discriminatorios", lo que confirma la interpretación de que los candidatos no son beneficiarios de la garantía de prioridad de permanencia, pero sí que son objeto de tutela antidiscriminatoria en materia sindical. ${ }^{56}$

Volviendo a la STSJ de Galicia, de 28 de septiembre de 2012 (Ro. 2183/2012), con cita a la STSJ de Andalucía (Sevilla), de 17 de marzo de 2000 (Ro. 4247/1999), señala que la garantía del derecho de opción en supuestos de despido declarado improcedente afecta sólo a dos partes (empresario y trabajador), pero la garantía de prioridad de permanencia afecta peyorativamente a un tercero (el trabajador despedido en vez del priorizado en la empresa, por aplicación de la lógica de la substitución), por lo que "la preferencia para ser adscrito a otros servicios y mantenerse en el puesto es prioridad que no puede reconocérsele -con trato peyorativo a otro trabajador- salvo mandato expreso de la ley, que sólo existe en los despidos colectivos u objetivos y para los representantes, no para los meros afiliados o candidatos".

Precisamente, la STSJ de Madrid, de 31 de mayo de 2018 (Ro. 764/2017), en un supuesto de suspensión colectiva de contratos de trabajo, señala de modo discutible que los candidatos sí que son titulares de la garantía de prioridad de permanencia, pero el razonamiento acto seguido se desliza hacia consideraciones relativas a que "ha existido una voluntad de represaliar a los actores por la actividad sindical que habían desarrollado, [...] por lo que entendemos que efectivamente se han vulnerado los derechos fundamentales de los trabajadores y por ello la medida es nula”. Por ello, lo que en verdad hace la sentencia es declarar la nulidad por conducta antisindical y discriminatoria por parte de la empresa, y no aplicar una prioridad de permanencia propiamente dicha.

\footnotetext{
${ }^{56}$ La STC 38/1981 de 23 de diciembre ( $R^{\circ}$. 189/1981) señala: "los actos que se denuncian como discriminatorios afectan a los candidatos en curso el proceso electoral y se les imputa propósitos de interferir decisivamente en la libre dotación de la representación obrera".
} 
En definitiva, los candidatos son objeto de protección en materia antidiscriminatoria y de garantía de su derecho fundamental a la libertad sindical, pero no son titulares de la garantía de prioridad de permanencia que establece el art. 68 b) ET, precisamente porque esta garantía pretende preservar la composición de los órganos representativos.

De cualquier modo, la ausencia de reconocimiento legal de la extensión de la garantía del art. 68 b) ET a los candidatos proclamados y no electos, puede paliarse vía negociación colectiva. En este sentido, y atendiendo al tenor literal del art. $68 \mathrm{y}$ art. $51.5 \mathrm{ET}$, nada obsta a que por convenio colectivo se amplíe la garantía de prioridad de permanencia prevista legalmente, de suerte que dicha garantía tenga un mayor alcance y/o beneficie a otros colectivos. Es decir, cabe pactar en convenio colectivo que los candidatos proclamados y no electos se beneficien también de la garantía de prioridad de permanencia.

La STSJ de Madrid, de 3 de febrero de 2017 (Ro. 1006/2016) aborda precisamente un supuesto en el que por convenio colectivo se habían ampliado las garantías de los representantes al momento de su proclamación como candidatos, y con proyección temporal adicional hasta tres años después de su cese en el cargo. En este sentido, señala: "La tesis [relativa a extender la garantía a los candidatos] no sería asumible desde la exclusiva perspectiva de aplicar el art. 68 b) ET, por cuanto la jurisprudencia ha interpretado que la garantía contenida en este precepto -prioridad de permanencia en casos de suspensión o extinción del contrato de trabajo por causas objetivas-, a diferencia del supuesto del párrafo c), incluye únicamente a los representantes de los trabajadores con mandato en vigor a la sazón de la decisión extintiva o suspensiva de que se trate.”

Por su parte, la STSJ de Madrid, de 21 de septiembre de 2015 (Ro. 310/2015) hacía referencia a un supuesto en el que el convenio colectivo contemplaba una previsión similar que, sin embargo, no fue aplicada por el tribunal. En consecuencia, la sentencia fue anulada por la STC 123/2018 de 12 de noviembre ( $\mathrm{R}^{\circ}$. 6331/2016), que considera que el TSJ de Madrid ignoró la disposición convencional al respecto, obviando la fuerza vinculante de los convenios colectivos y vulnerando el derecho fundamental a la libertad sindical. En resumen: cabe ampliar vía convenio colectivo la garantía de prioridad de permanencia a los candidatos proclamados, en cuyo caso habrá que aplicar la garantía prevista en la disposición convencional.

\subsubsection{Cese en el mandato representativo}

Por otro lado, otra cuestión que ha generado algún interrogante es la finalización del mandato del representante. En este sentido, la garantía de prioridad de permanencia deja de operar en el momento en que el representante cesa en su cargo, cuando expira su mandato, ya que al dejar de tener la condición de representante ya no se beneficia más de la garantía. Y ello a menos que por disposición convencional se pacte una extensión temporal de la garantía, como sucede en la citada STSJ de Madrid, de 3 de febrero de 2017 ( $\mathrm{R}^{\circ}$. 1006/2016), que extendía la garantía hasta los tres ańos siguientes al cese.

Ahora bien, sobre la finalización del mandato cabe añadir una matización, y debe tenerse presente el art. $67 \mathrm{ET}$, que señala que, una vez transcurridos los 4 años de duración del mandato de representante, "se mantendrán en funciones en el ejercicio de sus competencias y de sus garantías hasta tanto no se hubiesen promovido y celebrado nuevas elecciones". Por lo tanto, aun transcurrido el período de mandato efectivo, el representante sigue beneficiándose de la garantía en tanto continúe en funciones, y hasta el momento de celebrarse nuevas elecciones y definitivamente cesar en su cargo de representante.

En consecuencia, la garantía de prioridad de permanencia no se aplica "dentro del año siguiente a la expiración" del mandato. A este respecto, se ha planteado alguna confusión entre la 
garantía de prioridad de permanencia del apartado b) del art. 68 ET y la prohibición de despido o sanción con motivo del desempeño de las funciones representativas contenida en el apartado c) del art. 68 ET. Éste último señala que el representante tiene la garantía de "no ser despedido ni sancionado durante el ejercicio de sus funciones ni dentro del año siguiente a la expiración de su mandato, salvo en caso de que esta se produzca por revocación o dimisión, siempre que el despido o sanción se base en la acción del trabajador en el ejercicio de su representación”. Pues bien, en algún momento se ha intentado, erróneamente, extender a la garantía de prioridad de permanencia del apartado b) del art. 68 ET dicha previsión referida al ańo siguiente a la expiración del mandato. A este respecto, cabe señalar que las garantías de los apartados b) y c) del art. 68 ET son garantías distintas, y su extensión temporal también lo es, a tenor de la literalidad del precepto. Así, la garantía de prioridad de permanencia se aplica mientras esté vigente el mandato del representante, acabando la misma cuando el representante cesa en el cargo. En cambio, la prohibición de despido y sanción con motivo del ejercicio de las funciones representativas, sí que se extiende hasta el año siguiente al cese en el cargo.

Así lo ha sentado con toda claridad el Tribunal Supremo en la STS de 16 de septiembre de 2013 (Ro. 1636/2012, Sala de lo Social). ${ }^{57}$ El TS señala que el precepto distingue entre las dos garantías, y señala que las diferencias entre las mismas "son evidentes", al señalar que "la primera da la prioridad de permanencia mientras el representante está en activo, como tal, mientras que la segunda extiende sus efectos a las decisiones empresariales tomadas, incluso, durante el ańo posterior a su cese en las funciones representativas".

En este sentido, la prioridad de permanencia se aplica en despidos fundados en causas objetivas, y persigue, como se ha analizado en el epígrafe 2, garantizar que los trabajadores no se vean privados, en todo o en parte, de sus órganos representativos, por lo que la aplicación de la garantía tiene pleno sentido durante la vigencia del mandato, y no antes (candidatos) ni después. En cambio, la prohibición de despido o sanción con motivo del ejercicio de las funciones representativas se aplica en despidos fundados en causas subjetivas, y pretende evitar que la empresa adopte represalias contra el representante, por lo que tiene sentido que la garantía se extienda durante el año posterior al cese en el cargo representativo. Además, el TS destaca que para que opere esta última garantía, la motivación de la decisión de despido debe estar conectada con el ejercicio de las funciones representativas. Pues bien, debido a dichas diferencias entre las garantías y a la evidente distinta regulación y naturaleza de ambas, el TS considera que la garantía de prioridad de permanencia no puede extenderse al año posterior al cese del representante en el cargo.

A pesar de la claridad de los argumentos, es posible encontrar pronunciamientos posteriores en que alguna de las partes procesales reclamaba la extensión de la garantía de prioridad de permanencia al año posterior al cese. Así, cabe citar la STSJ de la Comunitat Valenciana, de 15 de diciembre de 2015 ( $\mathrm{R}^{\circ}$. 2800/2015), que señala que "no podemos estimar que exista una prioridad de permanencia en el caso de despido objetivo del representante que lo fue, pero ya no lo es en el momento del despido", con cita a la STS de 16 de septiembre de 2013 (Ro. 1636/2012, Sala de lo Social). Por su parte, la STSJ de Madrid, de 3 de febrero de 2017 (Ro. 1006/2016) recuerda que, "a diferencia del supuesto del párrafo c)" del art. 68 ET, la garantía de prioridad de permanencia “incluye únicamente a los representantes de los trabajadores con mandato en vigor a la sazón de la decisión extintiva o suspensiva de que se trate”.

\footnotetext{
${ }^{57}$ Citada en BELTRAN DE HEREDIA RUÍZ, Ignasi, 2020. Despido y extinción del contrato: síntesis de criterios jurisprudenciales. En: Una mirada crítica a las relaciones laborales [en línea]. Disponible en: https://ignasibeltran.com/extincion-contratodespido/ [consulta: 18/08/2020].
} 


\subsubsection{Momento de aplicación de la garantía: la comunicación de la medida extintiva}

Una vez sentado que para aplicar la garantía de prioridad de permanencia el representante debe tener en vigor su mandato como tal, cabe comentar cuál es el momento del procedimiento de despido colectivo en el que debe apreciarse si el mandato del representante está en vigor. A este respecto, el momento a tener en cuenta para ver si el representante tenía la condición de tal y puede beneficiarse de la garantía es el momento de efectuar el despido. En consecuencia, los tribunales han admitido que la garantía opere respecto de aquellos representantes que fueron elegidos durante el desarrollo del procedimiento de despido colectivo y que al inicio del mismo no tenían tal condición.

Así lo expresa la STS de 30 de octubre de 1989 (RJ 7465, Sala de lo Social), al señalar, refiriéndose a la antigua autorización administrativa, que "si en el tiempo transcurrido entre la resolución administrativa autorizante y la decisión empresarial que a su amparo la ejecuta o hace efectiva ocurre que los actores han sido elegidos representantes de los trabajadores, no ofrece duda que en ese segundo momento disfrutaban ya de pleno derecho de las garantías inherentes a tales nombramientos o designaciones, como depositarios de una voluntad colectiva que les ha investido de unas facultades representativas y de las prerrogativas que éstas llevan aneja, voluntad que se vería frustrada si estas últimas no fuesen reconocidas; sin que ello suponga en modo alguno aplicación retroactiva de los preceptos que las establecen, dado que éstos se aplican precisamente en el momento en que se lleva a efecto la extinción o suspensión de la relación laboral.”

En definitiva, la garantía opera si en el momento del despido el trabajador ostenta la condición de representante, como señala también la STS de 13 de septiembre de 1990 (RJ 7004, Sala de lo Social), al recordar que "la preferencia únicamente opera respecto a quien está en la situación garantizada en el momento de acordarse la medida" ${ }^{58}$

Los tribunales han exigido que el mandato del representante, a fin de que opere la garantía, esté vigente en el momento de comunicarse el despido, que es cuando el empresario adopta la decisión de despedir, y no en el momento de hacerse efectivo el mismo. Así se ha posicionado la STSJ de Galicia, de 28 de septiembre de 2012 (Ro. 2183/2012), y también la STSJ de Galicia, de 16 de julio de 2012 ( $R^{\circ}$. 1894/2012), que señala que "ha de estarse al acto de comunicación del despido, y no al momento en el que el mismo es efectivo".

\section{Conclusiones}

La prioridad de permanencia de los representantes de los trabajadores supone un límite específico a la facultad empresarial de seleccionar a los trabajadores afectados, en particular, por el despido colectivo. Se trata de una regla que excluye de la selección a un determinado trabajador por formar parte, en este caso, de la representación de los trabajadores. Sin perjuicio de incluir otras prioridades de permanencia en convenio colectivo o acuerdo alcanzado en el período de consultas, dicha protección se extiende legalmente a otros colectivos, como los delegados sindicales y también a los delegados de prevención, lo cual pretende proteger las funciones que desempeñan cada uno de estos colectivos.

El despido colectivo es un instituto en el que entran diversos intereses en juego, por lo que la selección de los afectados no es una cuestión que pueda mantenerse al margen. Si bien el empresario se ampara en el principio de libertad de empresa, las extinciones deben tener presentes otros inte-

\footnotetext{
${ }^{58}$ Además, es interesante comentar que en el supuesto discutido en la citada STS de 13 de septiembre de 1990, el trabajador había sido objeto de una suspensión del contrato y había adquirido la condición de representante una vez hecha efectiva la decisión suspensiva, por lo que el Tribunal considera que aplicar la prioridad de permanencia en un caso de dichas características sería retroactivo y afectaría a la seguridad jurídica.
} 
reses, como el respeto al derecho al trabajo -especialmente de los colectivos socialmente más vulnerables-, así como la representatividad de los trabajadores en la empresa y el derecho a la libertad sindical de los afiliados a un sindicato. Por ello, la prioridad de permanencia de los representantes pretende ser un elemento de ponderación en el amplio margen discrecional del que dispone el empresario para seleccionar a los afectados.

Para que opere la prioridad de permanencia se requiere, necesariamente, que exista más de un trabajador entre los que realizar la selección, uno de los cuales quedará excluido de dicha selección por acción de la mencionada prioridad para permanecer en la empresa (prioridad de no afectación). Debe rechazarse la conceptuación de dicha regla como "privilegio", pues la doctrina constitucional la considera un elemento de tutela de la representación de los trabajadores y también de la libertad sindical en supuestos de órganos sindicalizados, ya que pretende evitar, con carácter previo, eventuales afectaciones discriminatorias por motivos sindicales, que la tutela antidiscriminatoria sólo protege con carácter ex post.

Cabe destacar que la garantía de prioridad de permanencia tiene un alcance amplio pero relativo. En primer lugar, y por la conocida como lógica de la sustitución, la garantía no se circunscribe al estricto ámbito de afectación de la causa -si éste es parcial-, como podría ser el departamento, centro o unidad productiva donde incide la causa, sino que puede extenderse a toda la empresa. Por ello, la garantía se extiende al ámbito de representación del titular y no se ciñe necesariamente al ámbito de afectación de la causa de despido. Así, el trabajador titular de la garantía, si su ámbito de representación excede el del despido, puede permanecer en la empresa y ser sustituido en su afectación por otro trabajador que no necesariamente se encuentre dentro del ámbito de afectación del despido, sino fuera del mismo. Ahora bien, la garantía no es esgrimible con carácter absoluto, pues hay situaciones en las que no podrá aplicarse. Por supuesto no cabe aplicarla en casos de cierre total de la empresa, ya que no hay elementos de selección alternativos: todos los trabajadores serán seleccionados. Pero en los despidos parciales, también hay alguna limitación, y la misma viene determinada desde el punto de vista funcional: el representante o titular de la garantía sólo podrá permanecer si existe en la empresa un puesto funcionalmente equivalente o con funciones homogéneas que sean intercambiables y para las que el titular sea idóneo profesionalmente. De no ser así, simplemente la operatividad de la regla no sería posible para la empresa.

La existencia de la regla de prioridad de permanencia para los representantes de los trabajadores exige al empresario justificar expresamente la eventual afectación de los trabajadores titulares de la misma. Así, la normativa exige al empresario que justifique la afectación de un trabajador titular de dicha garantía, a fin de acreditar que la misma se produce por motivos ajenos a posibles causas de discriminación, así como justificar la aplicación de los criterios de selección al mismo y la ausencia de puestos equivalentes que pudieran ser desempeñados por el representante.

También es destacable que la garantía de prioridad de permanencia se ha extendido legalmente a otros sujetos más allá de los representantes legales de los trabajadores. La garantía se extiende también a los delegados sindicales ex art. 10.3 LOLS. La normativa en materia de prevención de riesgos laborales extiende la garantía a los delegados de prevención del art. 35 LPRL, y también a los trabajadores designados por el empresario ex art. 30.1 LPRL para ocuparse de las tareas de prevención, así como a los miembros del servicio de prevención propio creado ex art. 31.1 LPRL, no quedando incluidos aquí los denominados "recursos preventivos" del art. 32 bis LPRL.

Por último, los tribunales han dejado claro que un requisito para la operatividad de la garantía es la vigencia del mandato del representante. De este modo, cuando el representante cesa en su cargo, pierde la garantía, no siéndole aplicable la prohibición de despido "dentro del año siguiente a la expiración de su mandato" del art. 68 c) ET, que se refiere a despidos discriminatorios, y no a la prioridad de permanencia del art. 68 b) ET. Del mismo modo, la garantía tampoco se aplica antes 
de obtener la condición de representante, por lo que la misma no beneficia a los candidatos proclamados antes de resultar electos, con la salvedad de algún caso concreto en el que se demostró que el despido fue una actuación fraudulenta de la empresa que perseguía que los candidatos no resultasen electos. Aun en esos casos, lo que aplicaban los tribunales era más bien la tutela antidiscriminatoria, y no la regla de prioridad de permanencia como tal.

En definitiva, la prioridad de permanencia es una de las garantías principales con la que cuentan los representantes de los trabajadores para el mejor desempeño de sus funciones, y debe ser respetada a la hora de adoptar medidas de reestructuración empresarial, en particular el despido colectivo, a fin de preservar el ejercicio de las funciones que los representantes llevan inherentes a su cargo, así como para garantizar el respeto del derecho a la libertad sindical en supuestos de órganos sindicalizados.

\section{Bibliografía}

ALBIOL MONTESINOS, Ignacio, Extinción del contrato de trabajo por causas económicas o tecnológicas, En: BORRAJO DACRUZ, Efrén (dir.), Comentarios a las leyes laborales. El Estatuto de los Trabajadores, Tomo IX, Vol. 2, Artículos 49.5 a 9 y 51, Madrid, Edersa, 1989

ALBIOL MONTESINOS, Ignacio, El sindicato en la empresa. Madrid, Editorial Deusto, 1990

ALBIOL MONTESINOS, Ignacio, Comités de empresa y delegados de personal. Bilbao, Deusto, 1992

ÁLVAREZ ALONSO, Diego, La representación y participación de los trabajadores en la empresa, a la luz de la Jurisprudencia del Tribunal Supremo. Revista del Ministerio de Empleo y Seguridad Social. España, Ministerio de Empleo y Seguridad Social, núm. 143, 2019, p. 389-430

ÁLVAREZ ALONSO, Diego, Representación y participación de los trabajadores en la empresa: estudio de jurisprudencia y perspectivas de futuro. València, Tirant lo Blanch, 2020

BLASCO PELLICER, Ángel Antonio, Los expedientes de regulación de empleo. València, Tirant lo Blanch, 2009

BLASCO PELLICER, Ángel Antonio, La extinción del contrato de trabajo en la reforma laboral de 2012. València, Tirant lo Blanch, 2013

BLASCO PELLICER, Ángel Antonio, TALÉNS VISCONTI, Eduardo E., La forma y el procedimiento del despido. València, Tirant lo Blanch, 2018

BLASCO SEGURA, Benjamín, La extinción del contrato por causas tecnológicas o económicas: el expediente de regulación de empleo. Actualidad Laboral. España, Wolters Kluwer, núm. 33, 1992, p. 575-603

CASAS BAAMONDE, María Emilia, ESCUDERO RODRÍGUEZ, Ricardo, Representación unitaria y representación sindical en el sistema español de relaciones laborales. Civitas: Revista Española de Derecho del Trabajo. España, Civitas, núm. 17, 1984, p. 51-92

CERVERA SOTO, Teresa, CID BABARRO, Carlos, El despido colectivo: claves prácticas y análisis jurisprudencial. Valladolid, Lex Nova, 2016

CID BABARRO, Carlos, La representación sindical de la empresa. Valladolid, Lex Nova, 2014

DURÁN LÓPEZ, Federico, Análisis de la regulación jurídico-positiva del despido colectivo en España. Documentación Laboral. España, Cinca, núm. 22, 1987, p. 59-90

ESCUDERO RODRÍGUEZ, Ricardo, MERCADER UGUINA, Jesús Rafael, Manual jurídico de los representantes de los trabajadores. Madrid, La Ley, 2004

FERNÁNDEZ DOMÍNGUEZ, Juan José, Expedientes de regulación de empleo. Madrid, Trotta, 1993

GARCÍA MURCIA, Joaquín, Las garantías de los representantes de los trabajadores frente al despido: el tránsito hacia la unificación de doctrina, En: AA.VV., El Estatuto de los Trabajadores 
en la jurisprudencia del Tribunal Supremo. Estudios dedicados al Catedrático y Magistrado Don Antonio Martín Valverde, Madrid, Tecnos, 2015

GOERLICH PESET, José María, Los despidos colectivos. Art. 51 ET y normas concordantes, En: BORRAJO DACRUZ, Efrén (dir.), Comentarios a las leyes laborales: la reforma del Estatuto de los Trabajadores. Ley 11/1994, de 19 de mayo, y normas concordantes (Tomo II: el despido), Madrid, Edersa, 1994

GOERLICH PESET, José María, Desarrollo y contenido de las consultas, En: AA.VV., Los periodos de consultas, Colección Informes y Estudios, Serie Relaciones Laborales núm. 104, Madrid, Ministerio de Empleo y Seguridad Social, 2014

GOÑI SEIN, José Luis, El nuevo modelo normativo de despido colectivo implantado por la Ley de reforma laboral de 2012. Documentación laboral. España, Cinca, núm. 95-96, 2012, p. 25-56

LAHERA FORTEZA, Jesús, Representación y representatividad sindical: puntos críticos y propuesta de reforma. Papeles de economía española. España, Fundación de las Cajas de Ahorro (FUNCAS), núm. 156, 2018, p. 18-27

NIETO ROJAS, Patricia, Comisiones ad hoc y procesos de reorganización productiva empresarial. Una solución legal para empresas sin representación legal de los trabajadores, En: ESCUDERO RODRÍGUEZ, Ricardo (ed.), La negociación colectiva en las reformas de 2010, 2011 y 2012, Madrid, Cinca, 2012

NORES TORRES, Luis Enrique, El periodo de consultas en la reorganización productiva empresarial. Madrid, CES, 2000

PALOMO VÉLEZ, Ricardo, El modelo español de representación de los trabajadores en la empresa. València, Tirant lo Blanch, 2017

PUEBLA PINILLA, Ana de la, Las paradojas del despido colectivo tras la supresión de la autorización administrativa. Teoría y Derecho: revista de pensamiento crítico. España, Tirant lo Blanch, núm. 13, 2013, p. 129-156

RODRÍGUEZ RAMOS, María José, Despido colectivo: procedimiento, En: GORELLI HERNÁNDEZ, Juan (coord.), El despido: análisis y aplicación práctica, Madrid, Tecnos, 2004

ROQUETA BUJ, Remedios, La selección de los trabajadores afectados por los despidos colectivos. València, Tirant lo Blanch, 2015

SÁEZ LARA, Carmen, La representación colectiva de los trabajadores en la empresa. Revista del Ministerio de Trabajo e Inmigración. España, Ministerio de Trabajo e Inmigración, núm. 58, 2005, p. 315-342

SÁEZ LARA, Carmen, Reestructuraciones empresariales y despidos colectivos. València, Tirant lo Blanch, 2015

SAMPER JUAN, Joaquín, Los sistemas tradicionales y el régimen español de participación de los trabajadores, En: AA.VV., Gobierno de la empresa y participación de los trabajadores: viejas y nuevas formas institucionales, Salamanca, AEDTSS-Universidad de Salamanca, 2006

SEMPERE NAVARRO, Antonio Vicente, Las garantías de los miembros del comité de empresa. Civitas: Revista Española de Derecho del Trabajo. España, Civitas, núm. 100, 2, 2000, p. 1317 1340

SEMPERE NAVARRO, Antonio Vicente, PÉREZ CAMPOS, Ana Isabel, Las garantías de los representantes de los trabajadores (Estudio del Artículo 68 ET). Navarra, Aranzadi, 2004

TUDELA CAMBRONERO, Gregorio, Las garantias de los representantes de los trabajadores en la empresa. Madrid, Tecnos, 1988 